\title{
Comparing the Effectiveness of group Dialectical Behavior Therapy and Solution-Focused Brief Therapy on Self-Esteem, Cognitive-Emotional Regulation and Non-Suicidal Self-Injury in daughters
}

Ghazal Yasfard

M.A, Dept of General Psychology, Tehran North Branch, Islamic Azad University, Tehran, Iran.

Zahra Abaspour Azar

${ }^{*}$ Assistant Professor, Dept of Psychology, College of Humanities, Tehran North Branch, Islamic Azad University, Tehran, Iran. (Corresponding Author). Email: Z.abaspoorazar@jau-tnb.ac.ir

Seyed Ali Hosseini Almadani Assistant Professor, Dept of Psychology, College of Humanities, Tehran North Branch, Islamic Azad University, Tehran, Iran.

Received: 21 April 2019

Accepted: 20 August 2019

DOI: 10.29252/ijhehp.7.4.343

\section{ABSTRACT}

Background and Objective: Today, self-injury behavior has a significant prevalence among adolescents. The purpose of the present study was to compare the effectiveness of dialectical behavior therapy (DBT) and solution-focused brief therapy (SFBT) on self-esteem, cognitive emotion regulation, and non-suicidal self-injury behavior. Materials and Methods: This study was Quasi-experimental research. The statistical population consisted of 45 students studying in junior high school in Pardis city (2017-2018). They were committed non-suicidal self-injury behavior at least for once. Using random access sampling method, the sample divided into two experimental groups and a control group $(n 1=n 2=n 3=15)$. The research tools included Eysenck's self-esteem questionnaire (1976), Garnefski and Kraaij's cognitive emotion regulation questionnaire (2006), and Klonowski and Glenn's self-injurious behaviors and functions (2009). Experimental groups were under the dialectical behavior therapy and solution-focused (brief) therapy. The data were analyzed using multivariate analysis of covariance.

Results: There was a significant difference between the effectiveness of dialectical behavior therapy with solution-focused brief therapy on reducing self-injury behavior $(p<0 / 001)$ and cognitive emotion regulation $(p<0 / 05)$. There wasn't any significant difference in self-esteem variable. The mean scores of self- injury behavior for the dialectical behavior therapy group in post-test was significantly lower than the mean scores of the solution-focused brief therapy group and the control group. The mean of the dialectical behavior therapy group after a positive reappraisal was significantly higher than the mean of the control group.

Conclusion: The method of dialectical behavior therapy compared to Solutionfocused therapy has a greater impact on increasing the positive reappraisal subscale in cognitive emotion regulation and decreasing self-injury behavior.

Keywords: Dialectical Behavior Therapy, Solution-Focused Brief Therapy, Selfesteem, Cognitive Emotion Regulation, Self-Injury

Paper Type: Research Article.

Citation (Vancouver): Yasfard Gh, Abaspour Azar Z, Hosseini Almadani A. Comparing the Effectiveness of group Dialectical Behavior Therapy and Solution-Focused Brief Therapy on Self-Esteem, Cognitive-Emotional Regulation and Non-Suicidal Self-Injury in daughters. Iran J Health Educ Health Promot. Winter 2020;7(4): 343-358. [Persian]

- Citation (APA): Yasfard Gh., Abaspour Azar Z., Hosseini Almadani A. (Winter 2020). Comparing the Effectiveness of group Dialectical Behavior Therapy and Solution-Focused Brief Therapy on Self-Esteem, Cognitive-Emotional Regulation and Non-Suicidal Self-Injury in daughters. Iranian Journal of Health Education \& Health Promotion., 7(4),343-358. [Persian] 


\section{مقايسه اثربخشى رفتار درماذى ديالكتيكى و درمان كوتاه مدت راه حل محور بر عزت نفس، تنظيم شناختى هيجان و رفتار خود جرحى غيرخودكشى در دختران}

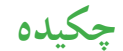

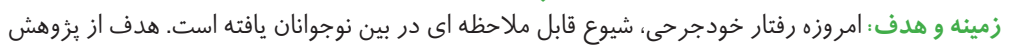

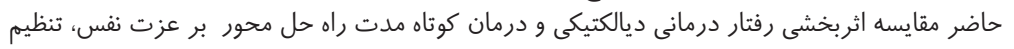

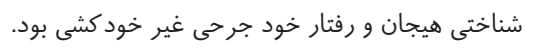

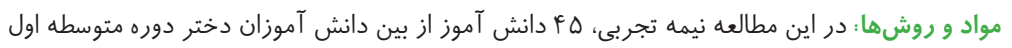

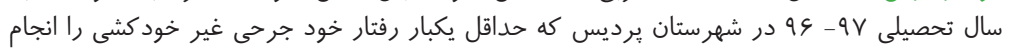

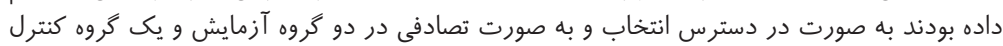

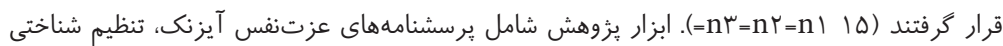

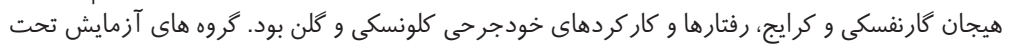

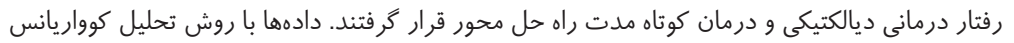
جندمتغيرى تحليل شدند.

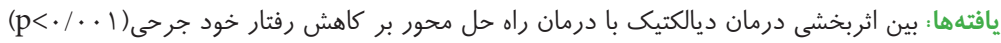

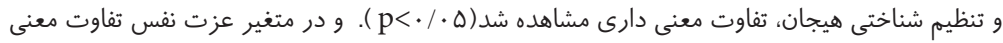

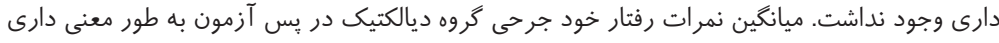

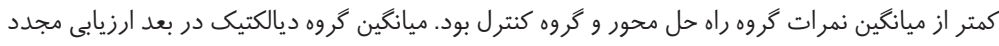

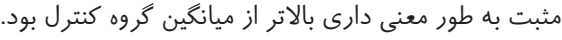

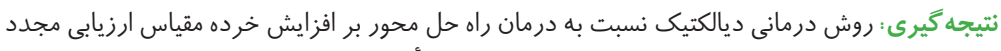

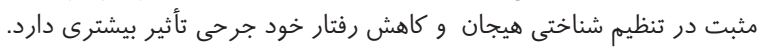

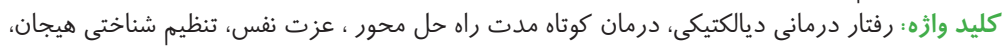

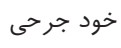

نوع مقاله : مطالعه :خزوهشى.

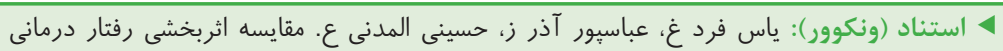

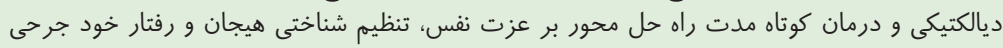

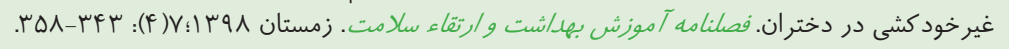

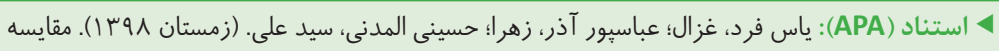

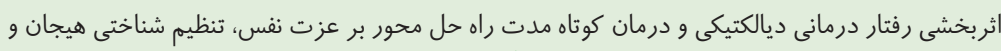

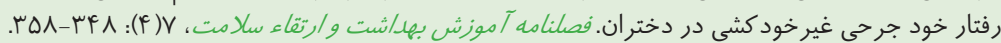

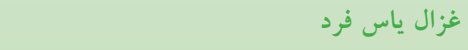

كارشناس ارشد، كروه روان شناسى عمومى، واحد تهران

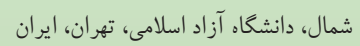

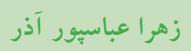

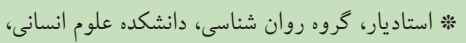

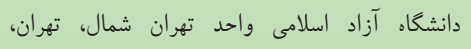
ايران(نو يسنده مسئول): Z.abaspoorazar@jau-tnb.ac.ir

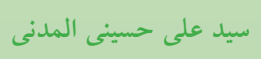

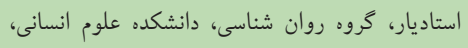

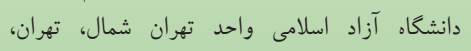

ايران

تاريخ دريافت: تاريخ يذيرش: 


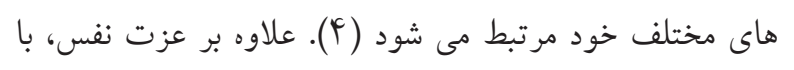

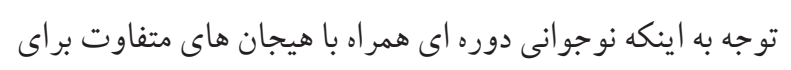

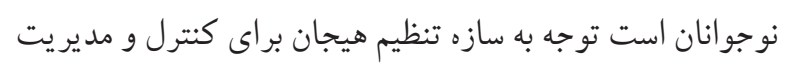

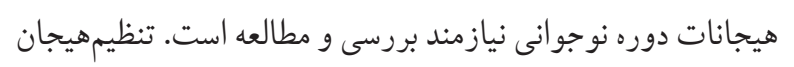
رامىتوان به صورت فرايندهايى تعريف كرد كه از طريق آن، افراد

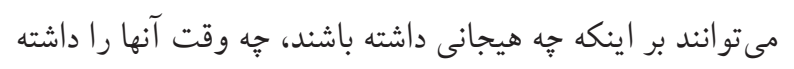

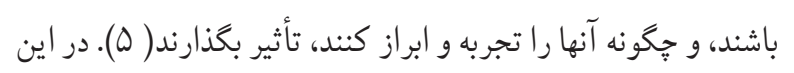

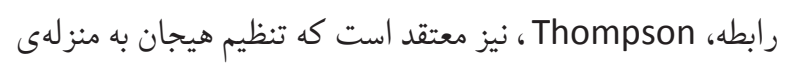
فرايندهاى درونى و بيرونى است كه مسئوليت كنترل، ارزيابى، و و

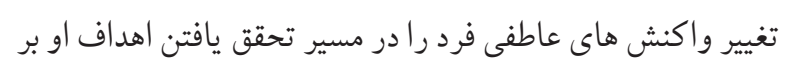
عهده دارند(9). بر رسى متون و مطالعات روان شناختى نشان ميدهدي كه تنظيم هيجان، عامل مهمى در تعيين سلامتى و داشتن عملكرد

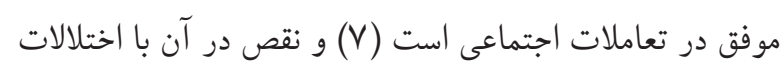
درون ريز (مانند افسردكى، اضطر اب، انزواى اجتماعى) و اختلالات

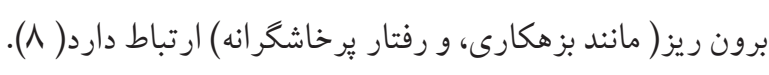
براساس مطالب مطرح شده در راستاى نقش مهم دو متغير عزت

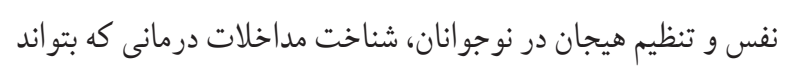

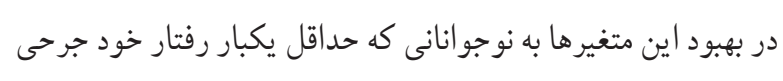

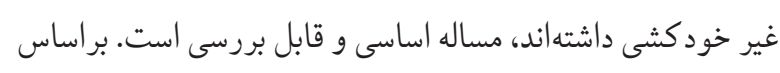

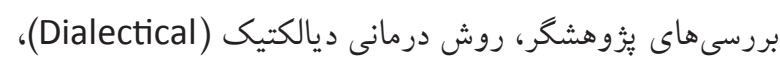

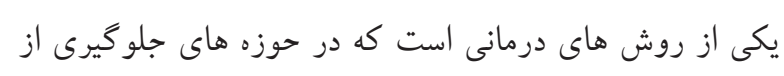

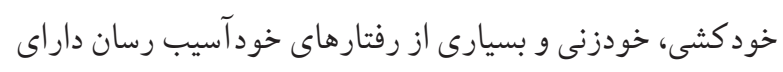

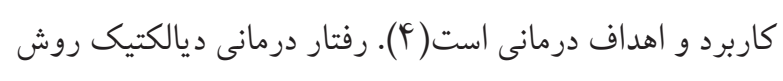

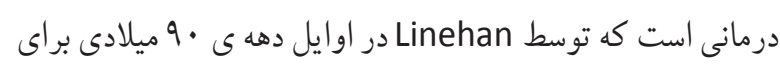
درمان بيماران مبتلا به اختلال شخصيت مرزى و ديكر بيماران مبتلا تونان

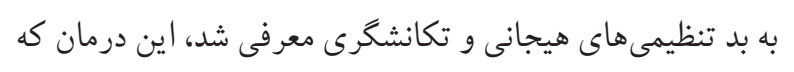
نوجوانى دورهاى مهم از رشد انسان مىباشد كه با تغييرات زيستىعصبى، هورمونى، فيزيولوزيكى و تغييرات اجتماعى همراه است. در طول اين دوره نوجوانان با عوامل استرسزاى متعددى كنار مى آيند (1). يكى از شايع ترين مشكلاتى كه امروزه در ميان نوجوانان رواج يافته است، رفتار خودجرحى(Self-InjuryBehavior) است كه به ميزان زيادى در همه فرهنگ هائ يافت مى شودد و تحت عنوان تخريب عمدى يا تغيير بافت هاى بدن بدون قصد آشكار و خود كشى (Suicidal)

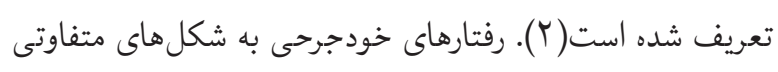

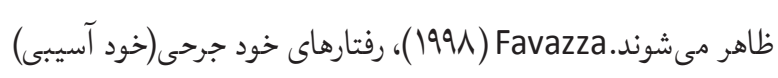
را به سه دسته تقسيم كرده است: 1 - رفتارهاى خود آسيبى شديد،

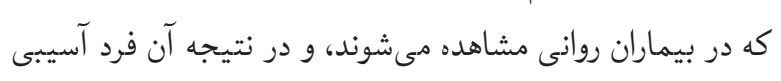
جدى به بافتهاى بدن خودش وارد مى كند، نظير قطع عضوى از

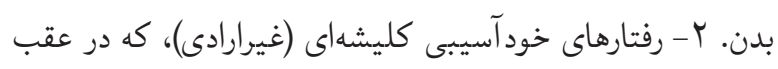
ماند كان ذهنى، اتيسم و يا سندروم توره مشاهده مىشود. در جنين

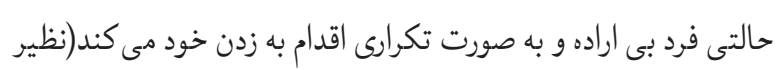

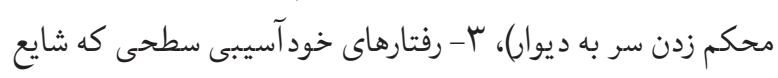
ترين نوع است و تحت تاثير مد يا عوامل ديكر انجام مى شودد: نظير

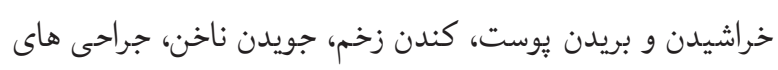
زيبايى و حكاكى يوست. كلونسكى Klonsky سيزده نوع انكيزه ( تنظيم هيجانى، تمايز خود از ديكران، تنبيه خود، مراقبت از خودي، ضدتجزيهاى، ضدخود كشى، حس جويى، تعلق به همسالان، اثركذارى

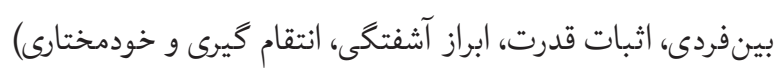

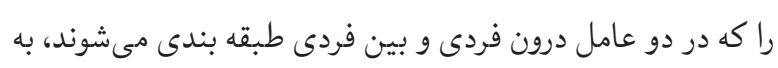

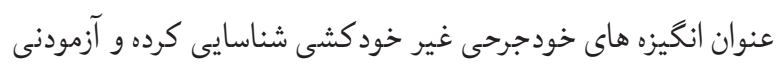

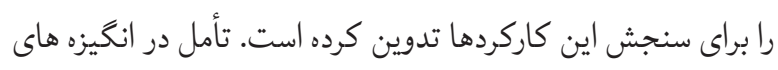
معرفى شده كلونسكى و يافتههاى حاصل از مصاحبه با آزمودنىها، يُوهش حاضر را به بررسى نقش عزت نفس(Self-Esteem) و

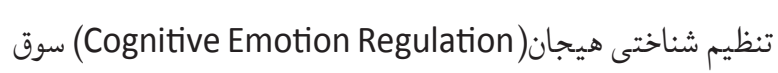
مى دهد؛ جرا كه به نظر مىرسد اين سيزده انگيزه در بروز رفتار خود جرحى غير خود كشى، مى توانند در زير جتر دو مؤلفه عزت نفس بنس 
دختر مقطع دبيرستان نشان داده است ب ا ب ٪ از نوجوانان در يك

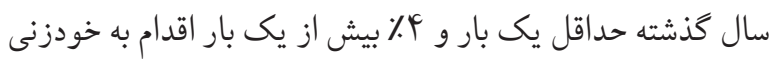

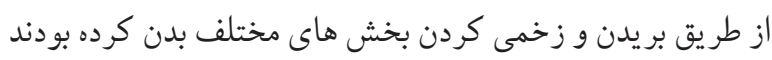

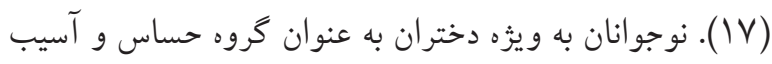

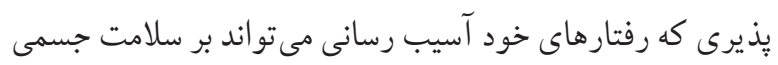

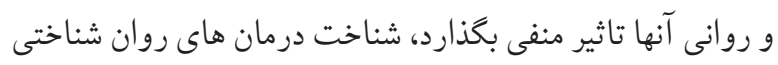
مناسب كه بتواند در ارتقاى سلامت روانى به آنها كمك نمايد،

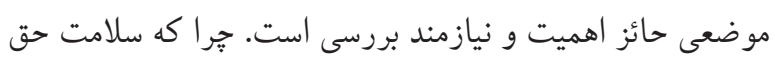

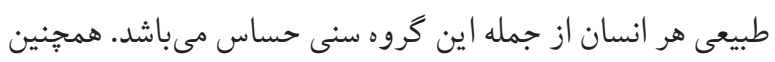

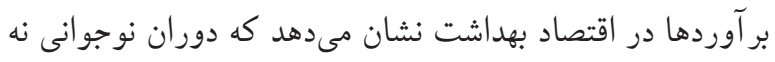
تنها از لحاظ كمى با ارزش ترين كروه سنى اجتماع مى باشد، بلكه

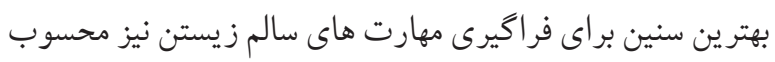

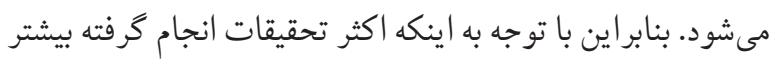

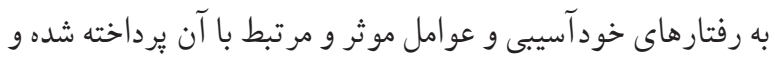

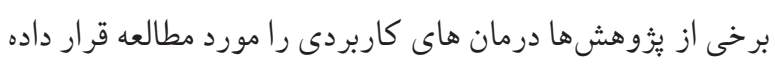

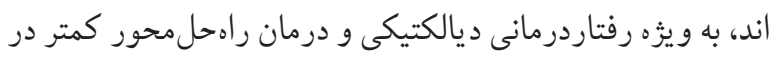

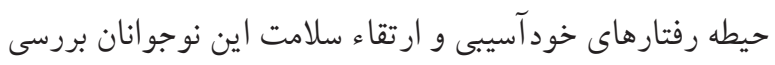

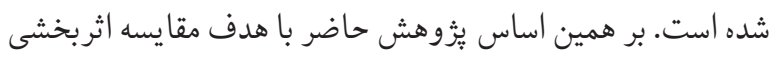
رفتاردرمانى ديالكتيكى با درمان كو تاه مدت راه حل محور به شيوه

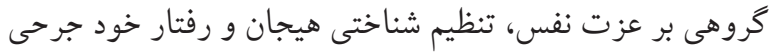

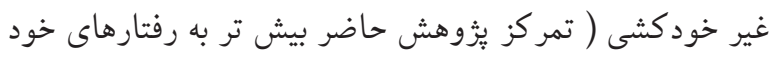

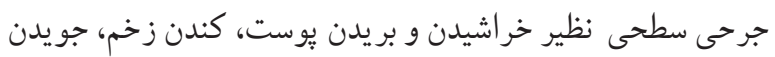

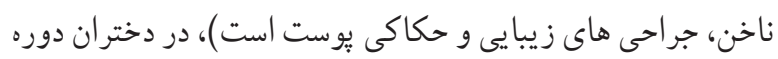

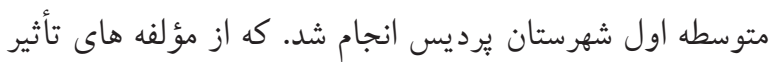
كذار بر سلامت روان نوجوانان مىباشد.

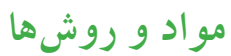
اين مطالعه از نوع نيمه تجربى باطرح ييش آزمون و پِّ آزمون

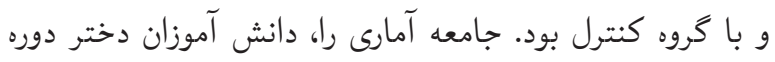
متوسطه اول سال تحصيلى وV- 99 دو شهرستان برديس تشكيل دادند. نمونه هاى يُؤوش شامل دانش آموزانى بود كه حداقل
از ابتداى تأسيس تاكنون موفقيت هاى بسيارى بدست آورده در

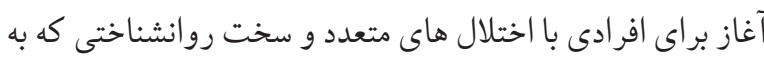

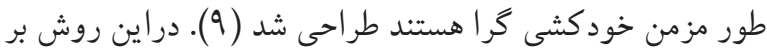
مهارت آموزى، يذ يذش و و اعتبار بخشى هيجانات تأكيد شده است.

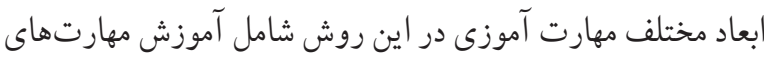

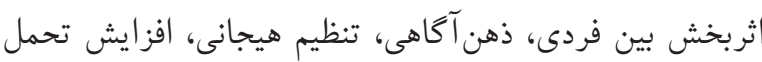

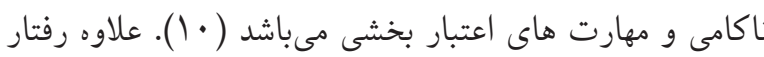

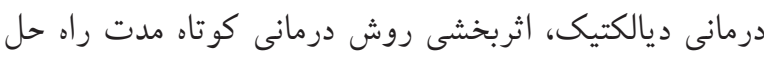
محور به روش كروهى(Solution-Focused Brief Therapy) بر عزتنفس، تنظيمهيجان و رفتار خودجرحى نوجوانان، مداخله

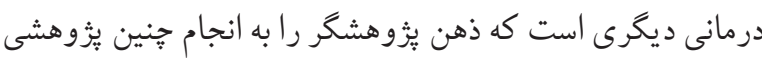

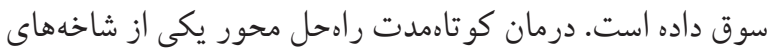
رويكرد پِت مدرن است كه با تمر كز به حل مساله، تغيير و توجه

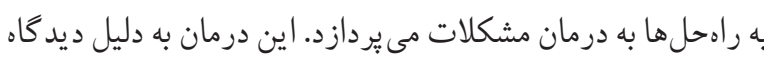

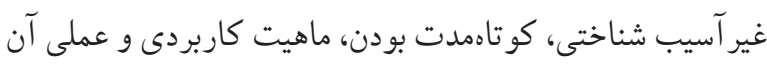

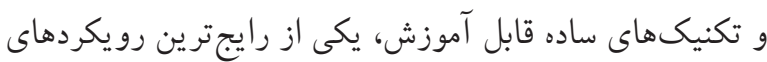

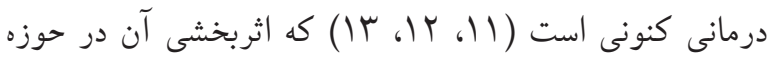

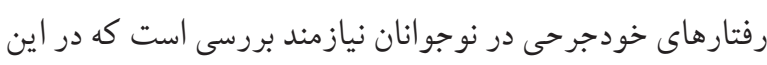
يُّوهش سعى شده بدان بِرداخته شود.

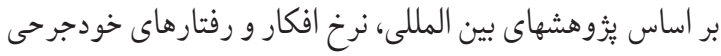
در گذر به نوجوانى به صورت بسيار زيادى افز ايش مى يابد و بيشترين

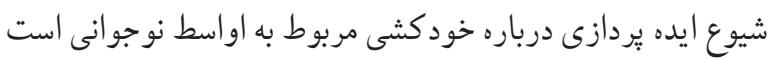

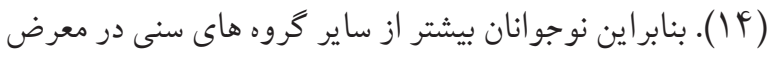

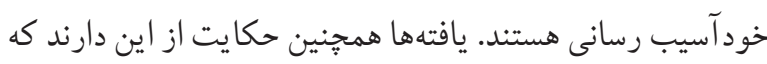

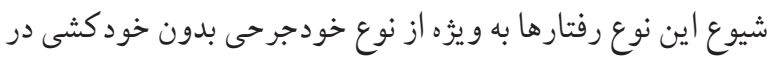

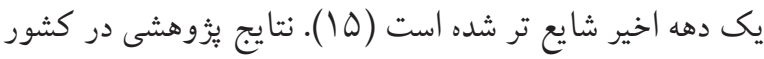

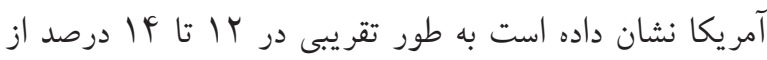

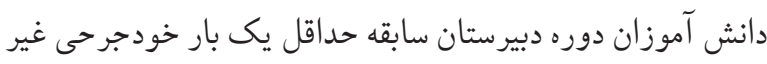
خودكشى وجو د دارد و دختران بيشتر از بسران سابقه اين رفتار را

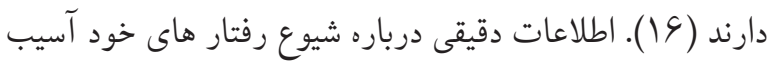

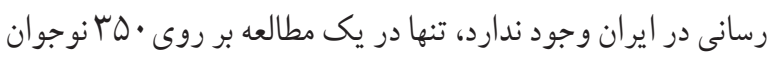


(داراى گواهينامه دوره هاى آموزشى ديالكتيك و اصول و فنون درمان راه حل محور از سازمان هاى نظام روان شناسى و مشاوره) در

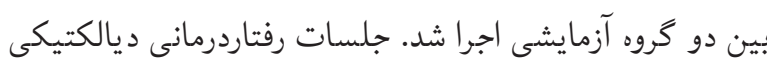
به طور خلاصه شامل اين موارد بود: در جلسه اول آشنايى اعضاء

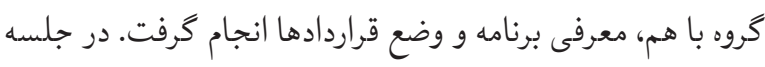

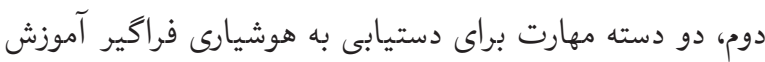
و تمرين داده شد. جلسات سوم تا ينجم به بخش اول از مولفهى تحمل بريشانى يعنى راهبردهاى بقا در بحران اختصاص داشت. در جلسات هفتم و هشتم به مولفهى تنظيم هيجانى برداخته شد.

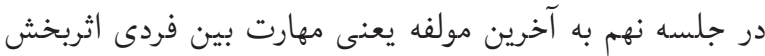

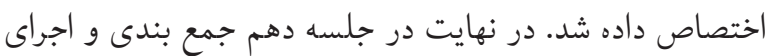
يس آزمون در جلسه دهم انجام شد.

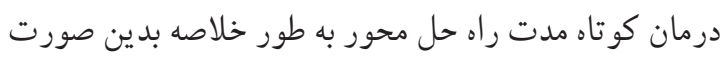

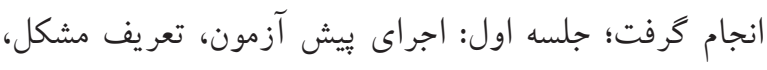
تبديل مشكل به اهداف قابل دسترس، بحث و مناظره درباره مشكل. جلسه دوم: بررسى تكاليف هفته قبل، كمك به شركت بت بـ

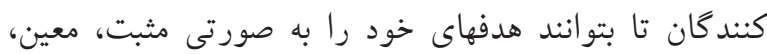
ملموس و قابل اندازه كيرى تدوين كنند. جلسه سوم: بررسى راه حل هاى برطرف كننده شكايات، فرمول بندى حلقه هاى راه حل

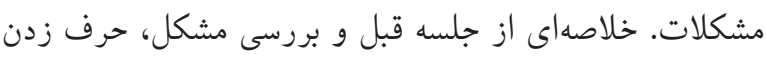

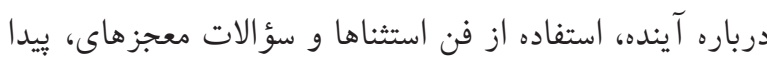

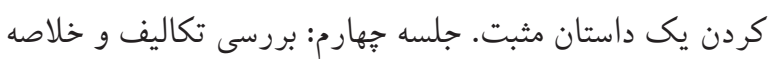
اى از جلسه قبل، توضيح فن شاه كليد و استفاده از آن، استفاده از فن سؤ الات مقياسى. جلسه ينجم: بر رسى تكاليف هفته قبل، ادامه

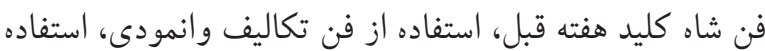

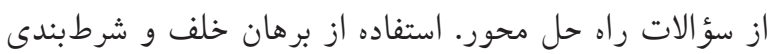
متناقض. جلسه ششم: خلاصهاى از جلسه قبل و بررسى تكاليف رحت

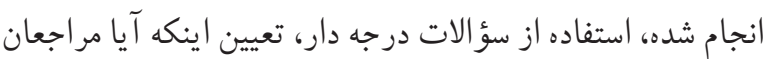
به اهداف درمان دست يافته اند؟ و اجراى پِ بس آزمون.

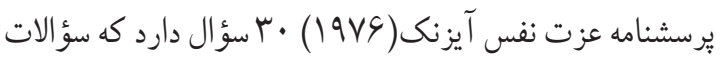

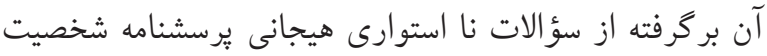

يكبار رفتار خود جرحى غير خودكشى را انجام داده بودند. حجم

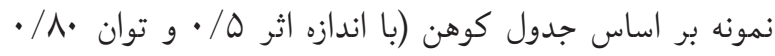

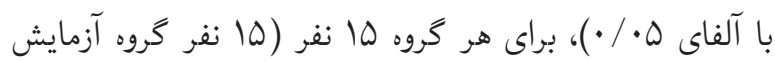

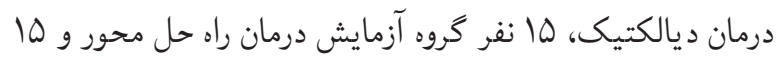

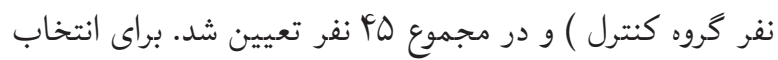

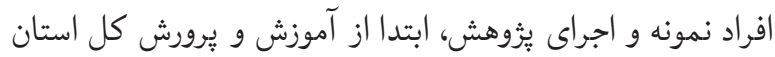

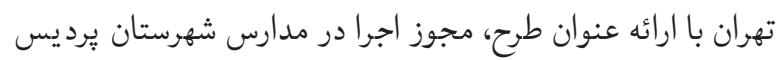

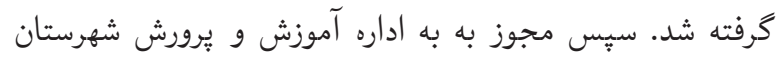

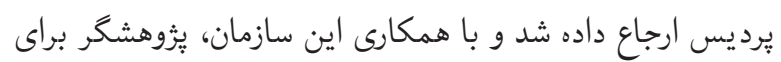

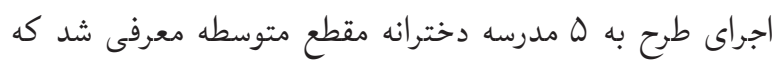
براساس ميزان همكارى مسئولين مدرسه و علاقه مربيان براى اجراى مدرى مدرسي

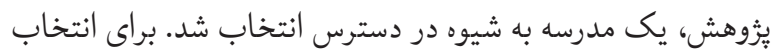
دانش آموزان، ابتدا در تمامى كلاسها به صورت مخته مختصر در در مورد

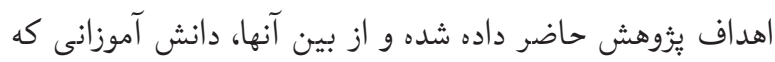
داراى سابقه حداقل يكبار رفتار خود جرحى غير خودكشى بودند و به صورت داوطلبانه حاضر به همكارى با يُوهشكر شدند، دانش آموز انتخاب و با توجه به ملاك هاى ورود ( جنسيت مؤنث،

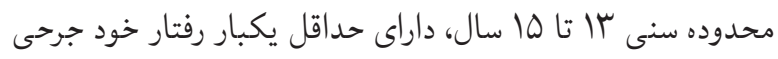

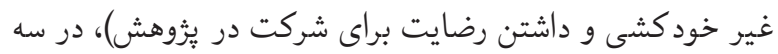

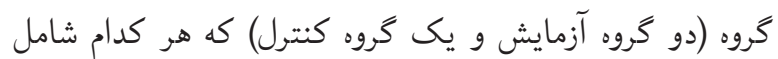
ا نفر بودند، به تصادف جايكزين شدند. (

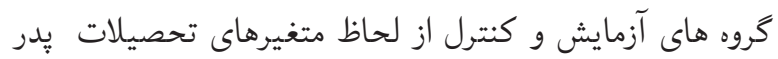

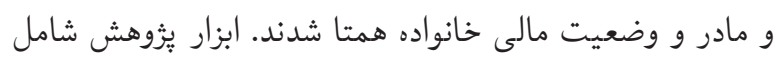
يرسشنامهاى عزتنفس Eysenck (19V9)، تنظيم شناختى هيجان Garnefski \& Kraaij Klonowski \& Galan

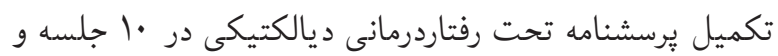

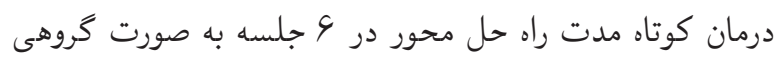
قرار گرفتند اما گروه كنترل هيج مداخله اى دريافت نكردند. محتواى جلسات درمانى تحت نظارت اساتيدى كه بركزار كننده دوره هاى آموزشى مورد نظر بودند، تدوين شد و توسط يُوهشكر درى 
فارسى اين يرسشنامه توسط Bl Beshtarat \& Bazaziyan از پايايى و روايى كافى برخوردار است.

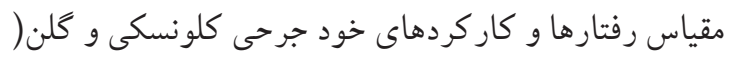

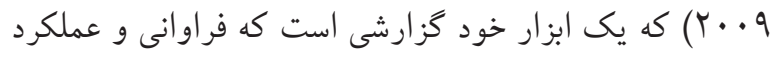
رفتار هاى خودجرحى غير خودكشى NSSI را ارزيابى مى كند.

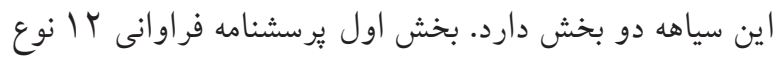
متفاوت رفتار هاى خود جرحى را كه به صورت عمدى (آكاهانه) اما نه به قصد خود كشى انجام مى شوند شامل: كوبيدن /زدن ، كاز

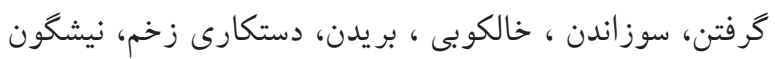

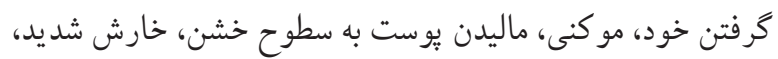

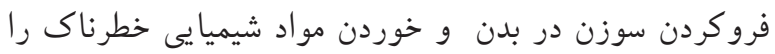

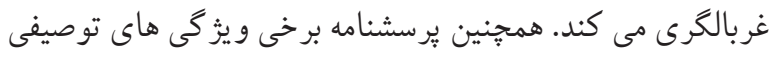
رفتار هاى آسيب رسان غير خود كشى گرا مانند: تاريخ اولين

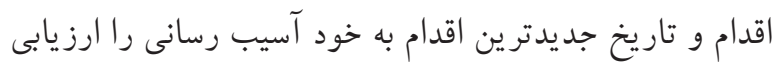

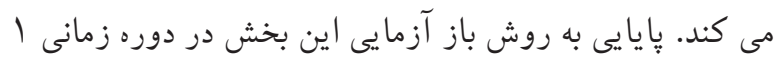

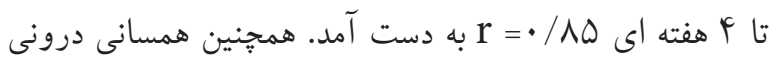

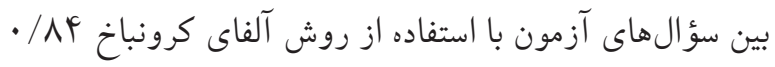

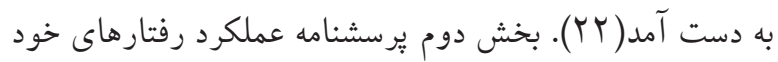

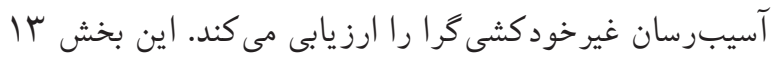

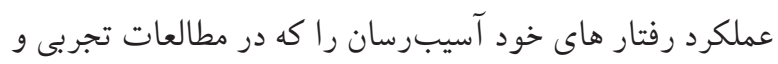

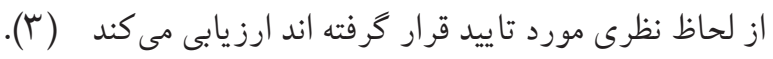
اين سا عملكرد به دو زير عامل كلى طبقه بندى شده اند: كاركرد هاى درون فردى( تنظيم عاطفى، ضد گسستكى، ضد خود كشى، نشان يُ يشانى و خود تنبيهى) و كار كرد هاى بين فردى (استقلال، حريم هاى بين فردى، تاثير بين فردى، وابستكى به همسالان،

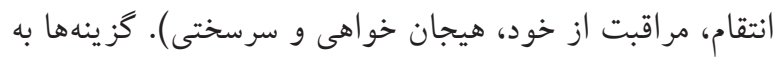
صورت ليكرت سه كز ينه اى تدوين شده است كه از • (كاملا غير

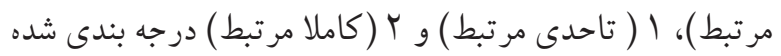

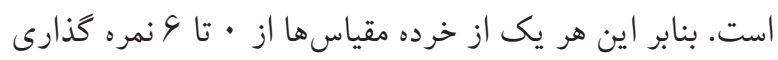
مى شوند. همجنين ميانگين نمره مقياس هاى كلى از جمع نمرات خرده مقياسها بر تعداد آنها به دست مى آيد.
آيزنخ است. آزمودنى براى هِاسخ دادن به هر ماده بايد يكى از

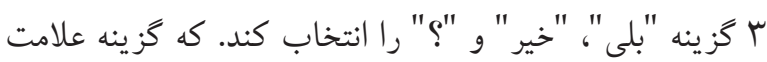

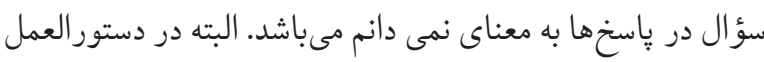

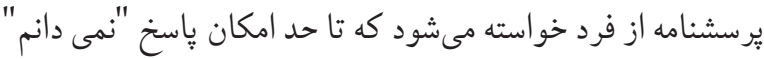

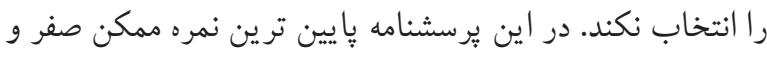

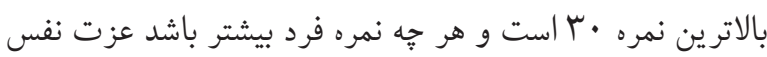

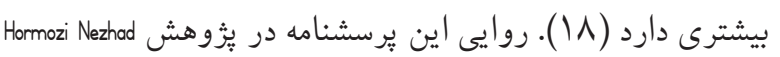

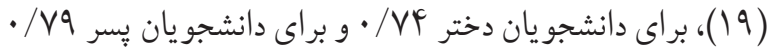

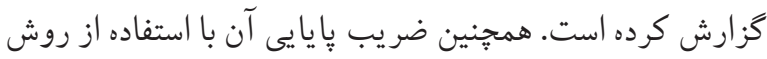

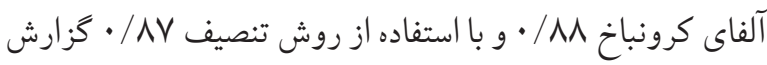
شده است.

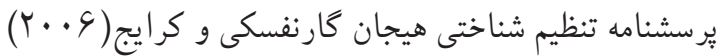
يك ابزار 11 مادة اى است و راهبردهاى تنظيم شناختى هيجانها هانيا

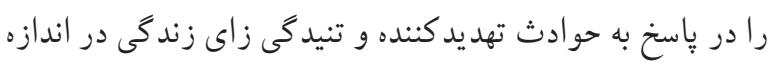

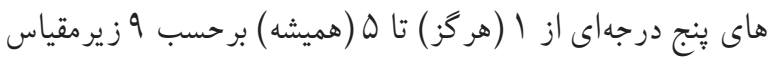
به اين شرح مى سنجد: خودسر زنشگرى؛ ديخر سرزنشگرى؛ تمر كز

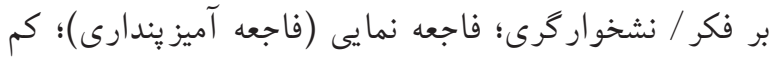

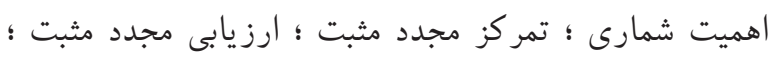
يذيرش ؛ تمركز مجدد بر برنامه ريزى . حداقل و حداكثر نمره در هر زيرمقياس به ترتيب و و • الست و نمرهُ بالاتر نشان

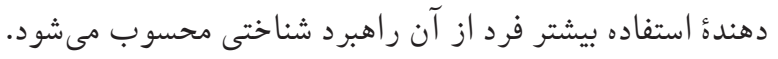
راهبرد شناختى تنظيمهيجان در برسشنامه تنظيم شناختى هيجان

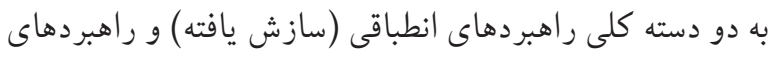
غير انطباقى (سازش نايافته) تقسيم مىشوند. زيرمقياس هاى كم اهميت شمارى، تمر كز مجدد مثبت، ارز يابى مجدد مثبت، يذيرش و تمركز مجدد بر برنامه ريزى؛ راهبردهاى سازش

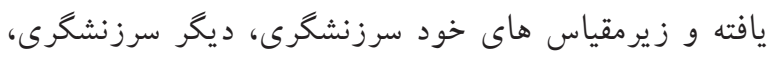

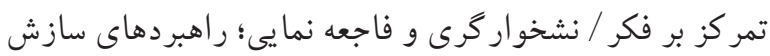

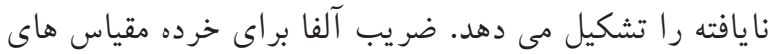

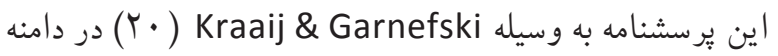

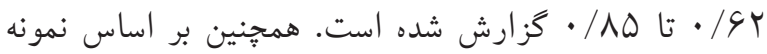


جرحى نرمال نيست. نمرات ساير گروهها نرمال است. نمرات

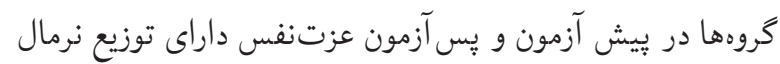

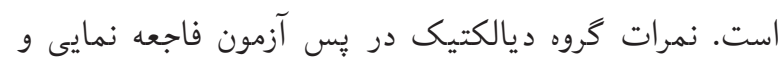
يذيرش و نمرات گروه راه حل محور در پِس آزمون سرزنش خود

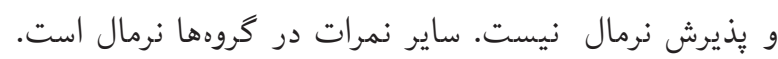

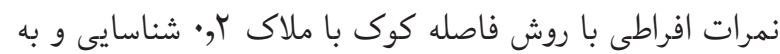

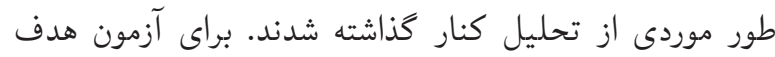

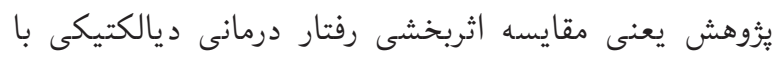

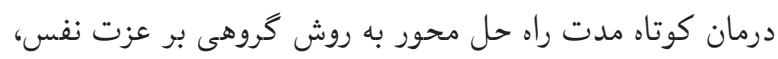

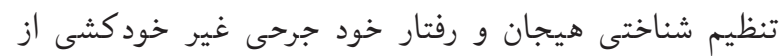

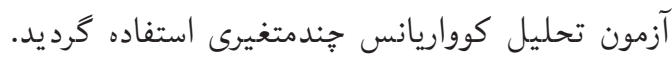

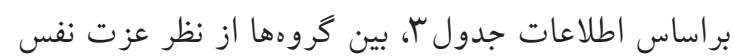

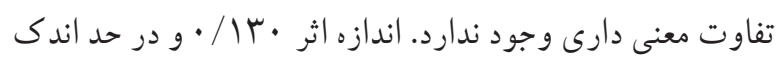

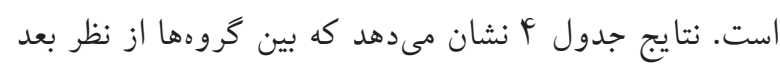
ارزيابى مجدد مثبت تفاوت معنى دارى وجود دارد دارد. اندازه اثر

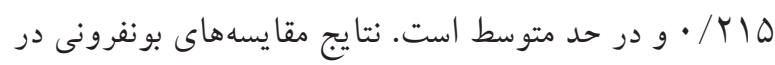

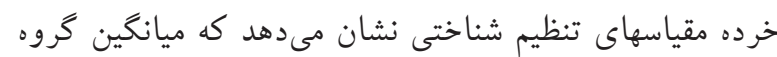

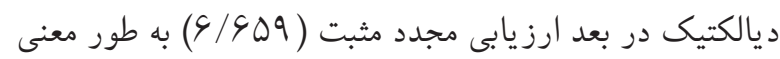

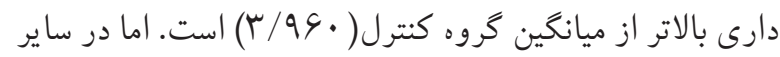
خرده مقياسها بين ميانكين گروه ديالكتيك با گروه راه حل حرول

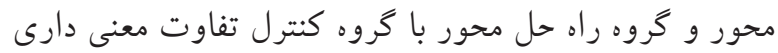
وجود ندارد. به عبارت ديكر، درمان ديالكتيك از اين نظر كه به مرون

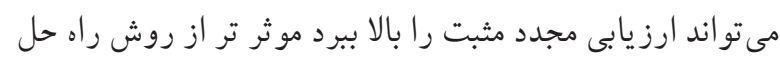
محور است. همان طور كه جدول ها نشان مىدهد، بين گروهها

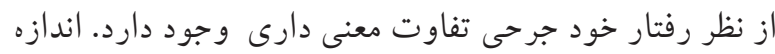

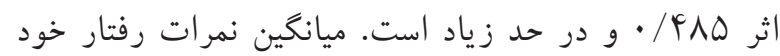

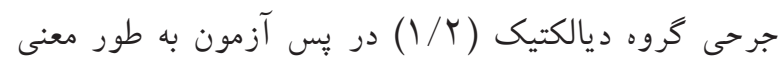

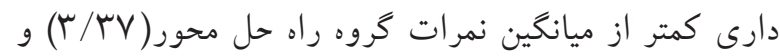

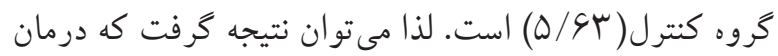
ديالكتيك مؤثرتر از درمان راه حل محور و هر دو درمان بهتر

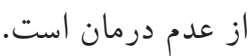

دادهها با كمك نرم افزار SPSS نسخه هY با خطاى هـ / • تحليل شدند. براى توصيف و تحليل دادهها از شاخصهاى فراو انى،

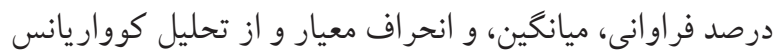

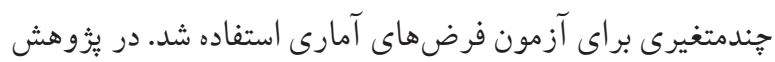

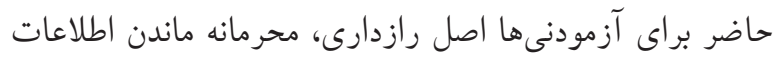

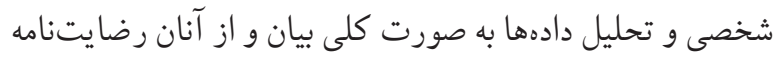

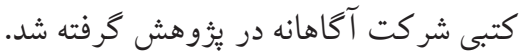

يافتهاه ها

شركت كنند گان شامل DF دانش آموز دختر دوره اول متوسطه داراى رفتار خودجرحى غيرخودكشى بودند كه حداقل يكبار

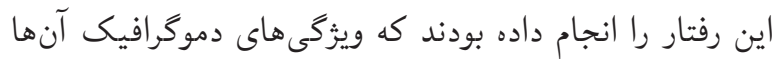

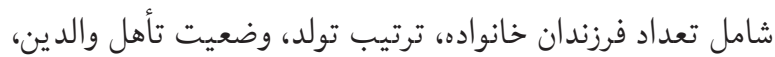
وضعيت سربرستى، شغل و تحصيلات پدر، شغل و تحصيلا

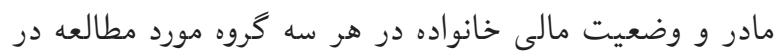
جدول ا كزارش شده است. به عنوان نمونه دختران اكثرا در گروه ديالكتيك ( درصد) ودر گروه كنترل ( •4 درصد) فرزند اول هستند. والدين

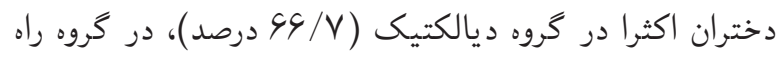

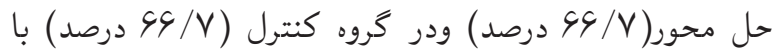
هم زندگى مى كنند. والدين دختران اكثرا در گروه ديالكتيك محرد ك. (94/V)

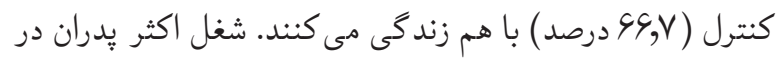

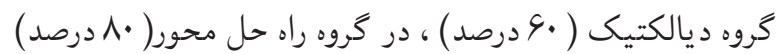
و در گروه كنترل ( •.ا درصد) غير دولتى است. وضعيت مالى

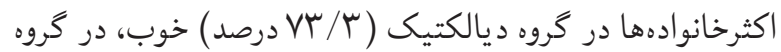

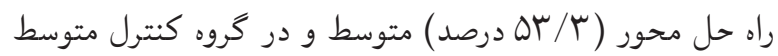

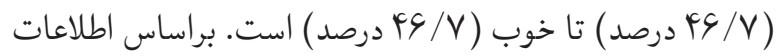

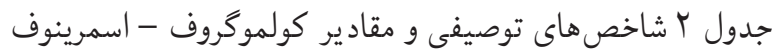
و سطوح معنى دارى آن همكى حاكى از آن است كه توزيع

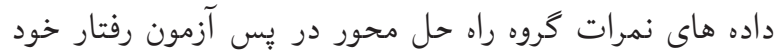


جدول ا. توزيع فراوانى مشخصات فردى - اجتماعى در كَروه هاى آزمايش و كنترل

\begin{tabular}{|c|c|c|c|c|c|c|c|}
\hline \multicolumn{2}{|c|}{ كنترل } & \multicolumn{2}{|c|}{ مداخله راه حل محور } & \multicolumn{2}{|c|}{ مداخله ديالكتيك } & \multirow{2}{*}{\multicolumn{2}{|c|}{ متغير هاى فردى - اجتماعى }} \\
\hline درصد & تعداد & درصد & تعداد & درصد & تعداد & & \\
\hline$G / V$ & r & س & r & $r$. & r & 1 & \multirow{5}{*}{ نعداد فرزندان خانواده } \\
\hline$r G / V$ & $\checkmark$ & س & $\wedge$ & 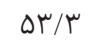 & $\wedge$ & r & \\
\hline 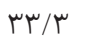 & 0 & $r s / V$ & r & 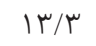 & r & r & \\
\hline$G / V$ & 1 & $s / V$ & 1 & 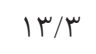 & r & f & \\
\hline$G / V$ & 1 & . & · & . & · & $\Delta$ & \\
\hline c. & 9 & س & $\wedge$ & ( & $\wedge$ & اول & \multirow{3}{*}{ ترتيب تولد } \\
\hline $1 r / \mu$ & r & 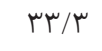 & $\Delta$ & $f \& / V$ & $\checkmark$ & 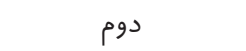 & \\
\hline$r s / V$ & r & 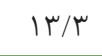 & r & . & . & آخر & \\
\hline$G S / V$ & $1 \cdot$ & SG/V & 1 . & ૬૬/V & $1 \cdot$ & باهم & \multirow{2}{*}{ وضعيت تأهل والدين } \\
\hline 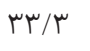 & $\Delta$ & ( & $\Delta$ & 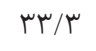 & $\Delta$ & جدا از هم & \\
\hline $49 / V$ & 1. & SG/V & 1 . & SG/V & 1. & يدر و مادر & \multirow{4}{*}{ وضعيت سريرستى } \\
\hline 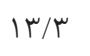 & r & . & . & 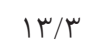 & r & 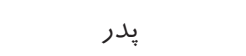 & \\
\hline $1 \mu / \mu$ & r & س/س & $\Delta$ & س & r & مادر & \\
\hline$G / V$ & 1 & & . & $s / V$ & 1 & هيجكدام & \\
\hline . & $\cdot$ & $s / V$ & 1 & $s / V$ & 1 & بيكار & \multirow{3}{*}{ شغل پيدر } \\
\hline . & . & 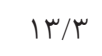 & r & 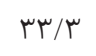 & $\Delta$ & 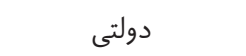 & \\
\hline $1 \cdots$ & 10 & $\wedge$. & ir & 4. & 9 & 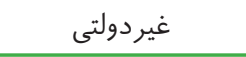 & \\
\hline$r G / V$ & r & $r G / V$ & f & $r \varphi / V$ & q & زير ديڤلم & \multirow{4}{*}{ تحصيلات يدر } \\
\hline$\Delta \mu / \mu$ & $\wedge$ & f. & 4 & $r \& / V$ & $\checkmark$ & دييلم و فوق دييلم & \\
\hline$r$. & r & $r$. & r & $s / V$ & 1 & 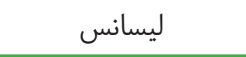 & \\
\hline . & . & 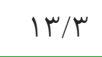 & r & $r$. & r & فوق ليسانس و بالاتر & \\
\hline$V \pi / \mu$ & 11 & $V \Psi / \mu$ & 11 & $V \mu / r$ & 11 & خانه دار & \multirow{3}{*}{ شغل مادر } \\
\hline$s / V$ & 1 & . & . & . & . & دولتى & \\
\hline$r$. & r & $r G / V$ & f & rG/V & f & غير دولتى & \\
\hline $\mathrm{IV} / \mathrm{A}$ & r & س/ & r & $r$. & r & زير ديڤم & \multirow{4}{*}{ تحصيلات مادر } \\
\hline$V \mu / \mu$ & 11 & S૬/V & 1 . & $\varsigma \hookrightarrow / V$ & 1. & دييلم و فوق ديڤلم & \\
\hline$s / V$ & 1 & $r$. & r & $s / V$ & 1 & ل ل ليسانس & \\
\hline . & . & . & . & $s / V$ & 1 & فوق ليسانس و بالاتر & \\
\hline . & . & س & $r$ & . & . & ضعيف & \multirow{4}{*}{ وضعيت مالى خانواده } \\
\hline$\varphi q / V$ & $\checkmark$ & 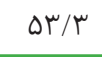 & $\wedge$ & $r s / V$ & q & متوسط & \\
\hline$\leftarrow \& / V$ & v & $r G / V$ & r & $V \mu / r$ & 11 & خوب & \\
\hline$G / V$ & 1 & $s / V$ & 1 & . & . & بسيار خوب & \\
\hline
\end{tabular}




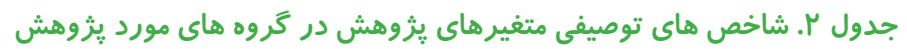

\begin{tabular}{|c|c|c|c|c|c|c|c|c|}
\hline سطح معنى & كولموگروف & كشيدكى & 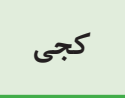 & انحراف & 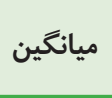 & 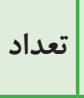 & 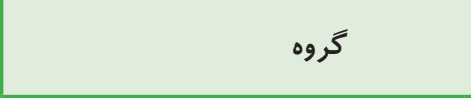 & \\
\hline$\cdot / r$ & .110 & $-\cdot / r \Delta r$ & $-\cdot /$ rrg & $r / \Delta 91$ & $\mathrm{~V} / \cdot \cdot$ & 10 & رفتار خودجرحى - يِيش آزمون & \multirow{2}{*}{ دروه آزمايشى } \\
\hline.$/ l F r$ &.$/ 19 r$ &.$/ 419$ &.$/ 9 \vee \mu$ & $r / l \cdots$ & $r / I r$ & 10 & رفتار خودجرحى - پِ آزمون & \\
\hline$\cdot / r$ & $\cdot / l \Delta r$ & $-1 / r \mu \Delta$ & $-\cdot / \cdot r$ & $r / \cdot I V$ & $\Delta / V^{\mu}$ & 10 & رفتار خودجرحى - يیش آزمون & \multirow{2}{*}{ راهوه آزمايشى حل محور } \\
\hline.$/ .1$ & . / rqu & I/VFF & $1 / 4 \Delta \Delta$ & $r / r \Delta V$ & 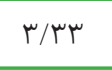 & 10 & رفتار خودجرحى - يس آزمون & \\
\hline$\cdot / l \Delta F$ &.$/ 119$ & $\cdot / \wedge \wedge \Delta$ & $\cdot / \wedge V^{\mu}$ & $r / \wedge 90$ & $r / 9 V$ & 10 & رفتار خودجرحى - يِش آزمون & \multirow{2}{*}{ كروه كنترل } \\
\hline$\cdot / r$ &.$/ 104$ & $-\cdot / r 19$ &.$/ 194$ & $r / f r r$ & $r / 9 r$ & 10 & رفتار خودجرحى - پِس آزمون & \\
\hline$\cdot / r$ & $\cdot 11 \cdot 0$ & 每 & $\cdot / \mu c \cdot-$ & V/AFr & $r V / r v$ & 10 & عزت نفس - يِش آزمون & \multirow{2}{*}{ كروه آزمايشى } \\
\hline$\cdot / r$ & .110 & $\cdot / 4 \vee 1$ & $\cdot / 4 q \vee$ & $9 / 1 \Lambda F$ & $\mu r / \cdot V$ & 10 & عزت نفس - پِ آزمون & \\
\hline ( ) & $\cdot / r r q$ & $\cdot / 9 \wedge \mu$ & $\cdot / V \Delta V-$ & $\Delta / \Delta \wedge 1$ & $r \mathrm{~V} / \cdot$ & 10 & عزت نفس - يِش آزمون & \multirow{2}{*}{ راه حل محهو آزمايشى } \\
\hline$\cdot / r$ & $\cdot / 101$ & $1 / \cdot v V$ & $\cdot / 4 \cdot r$ & $r / \wedge \Delta$ & س & 10 & عزت نفس - پس آزمون & \\
\hline$\cdot / r$ & $\cdot / \mathrm{VA}$ & $-1 /$ HAV & $.1199_{-}$ & V/OVD & $\mu F / \mu r$ & 10 & عزت نفس - يِش آزمون & \multirow{2}{*}{ كروه كنترل } \\
\hline$\cdot / r$ &.$/ 1 s \mu$ & $-1 / 119$ & $\cdot / \cdot+\Lambda_{-}$ & $1 / 119$ & $r \Delta / v r$ & 10 & عزت نفس - پِس آزمون & \\
\hline$\cdot / r$ &.$/ I V^{c}$ & $-1 / 4 V I$ & $\cdot / \mu \cdot r$ & $\mu / \cdot r r$ & $4 / \cdot$ & 10 & سرزنش خود- يِيش آزمون & \multirow{18}{*}{ دروه آزمايشى } \\
\hline$\cdot / r$ &.$/ 19 V$ &.$- / \mathrm{9} 1$ & $-\cdot / \mu F i$ & $r / 091$ & $4 / \cdot$ & 10 & بذيرش - بيش آزمون & \\
\hline$\cdot / r$ &.$/ 189$ & $-\cdot / V V r$ &.$- / 9 \vee 9$ & r/rл. & $V / 9 V$ & 10 & تمر كز بر فكر /نشخواركرى- ييش آزمون & \\
\hline$\cdot / \cdot r$ & . / r人ץ & $r / \wedge \varsigma 1$ & $1 / V \Delta 9$ & $r / \cdot r \Lambda$ & $r / 4$. & 10 & تمركز مجدد مثبت - يِش آزمون & \\
\hline$\cdot / r$ &.$/ 101$ & $-1 /|f|$ & $-\cdot / q \mu 1$ & r/VYr & $4 / 1 \mu$ & 10 & تمركز مجدد بر برنامه ريز - ييش آزمون & \\
\hline$\cdot / r$ & .1109 & $-\cdot / \wedge F$ &.$/ r \wedge 1$ & $r / 09 V$ & $\Delta / \wedge$. & 10 & ارزيابى مجدد مثبت- بيش آزمون & \\
\hline$\cdot / r$ &.$/ 1 \mathrm{~V}$ &.$- / 1 m p$ &.$/ V{ }_{1}$ & r/FVO & $r / \wedge V$ & 10 & كم اهميت شمارى - ييش آزمون & \\
\hline.$/ .19$ & $\cdot / T F$ & $-1 / V V V$ & $-\cdot /$ KFT & $r / l r v$ & S/AV & 10 & فاجعه نمايى - پِيش آزمون & \\
\hline$\cdot / \cdot r$ & $\cdot / r \wedge 1$ & $-1 / V I r$ & $\cdot /$ rVo & $\mu / 1 \cdot \Delta$ & $s / \cdot V$ & 10 & سرزنش ديخران- يِش آزمون & \\
\hline$\cdot / \cdot 4$ & . /rTo & $-\cdot / \mu$. & $\cdot / V V^{C}$ & r/VYr & $r / \wedge V$ & 10 & سرزنش خود- يِ آزمون & \\
\hline.$/ \cdot \Delta$ &.$/ r \& 9$ & $-1 / \wedge \& V$ &.$/ 1 r \Delta$ & $r / 910$ & $s / V^{\mu}$ & 10 & يذيرش - بِ آزمون & \\
\hline$\cdot / r$ &.$/ 145$ & $-I / Y F$ & $-\cdot /$ TFF & $r / V \Psi$ & s/1. & 10 & تمركز بر فكر/نشخوارگرى- يس آزمون & \\
\hline$\cdot / r$ &.$/ 1 \vee \Delta$ &.$/ F V F$ & .1909 & $r / r s q$ & $r / A V$ & 10 & تمر كز مجدد مثبت - پِ آزمون & \\
\hline$\cdot / r$ &.$/ 1 F F$ &.$/ 111$ & $\cdot / \mathrm{VI}$ & r/TOS & $\Delta / \mathscr{A V}$ & 10 & تمركز مجدد بر برنامه ريزى - بس آزمون & \\
\hline$\cdot / r$ &.$/ 1 \Delta v$ & $-1 / \Delta \mu r$ &.$/ \cdot r$ & $r / 99 \mu$ & $4 / \cdot V$ & 10 & ارزيابى مجدد مثبت - يس آزمون & \\
\hline.$/ 110$ &.$/ 191$ & $\cdot 11 \cdot 9$ & $\cdot / 4 \cdot V$ & $r / r 99$ & $\Delta / \cdot \cdot$ & 10 & كم اهميت شمارى- يِ آزمون & \\
\hline$\cdot / r$ &.$/ 1 \Delta v$ & $-.19 \cdot 9$ & .1014 & $r / \Delta F Q$ & $\Delta / \cdot V$ & 10 & فاجعه نمايى - پس آزمون & \\
\hline$\cdot / r$ & . & $-1 / r \cdot \Delta$ &.$/ 1 r \Lambda$ & $r / 9 \cdot \Lambda$ & $\Delta / \Lambda$. & 10 & سرزنش ديكران - هِ آزمون & \\
\hline
\end{tabular}




\begin{tabular}{|c|c|c|c|c|c|c|c|c|}
\hline 1 & $\cdot /$ rr人 & $\Delta / V F V$ & $r / r \mid r$ & $1 / G 4 \wedge$ & $\Delta / \cdots$ & 10 & سرزنش خود - يِش آزمون & \multirow{18}{*}{ راه حل مل محور آزمايشى } \\
\hline$\cdot / 1 \cdot 1$ & $\cdot / r \cdot r$ & $-\cdot / \mathbb{F} \Delta r$ & .1919 & $r / F \mid F$ & $\Delta / \mathbb{F}^{+}$ & 10 & يذيرش - پِيش آزمون & \\
\hline$\cdot / r$ & $\cdot / I V r$ & $-\cdot / \wedge \Delta 1$ & 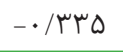 & l/AV & V/ru & 10 & تمركز بر فكر /نشخوارگرى- يِش آزمون & \\
\hline.$/ \cdot s^{\mu}$ & $\cdot / r \mid F$ & 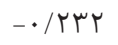 & $-\cdot / \cdot \Delta \cdot$ & I/I ro & r/AV & 10 & تمر كز مجدد مثبت - ييش آزمون & \\
\hline .1 .99 & $\cdot / r \mid r$ & $-1 / 0 \wedge \varsigma$ & $\cdot /$ mF & r/rrs & G/Or & 10 & تمركز مجدد بر برنامه ريزى- يِش آزمون & \\
\hline$\cdot / r$ & $\cdot / 1 \mathrm{~V} \Delta$ & $-\cdot / \wedge \Delta S$ & $-\cdot / 1 \mu f$ & $r / F V D$ & $s / \mathbb{F V}$ & 10 & ارزيابى مجدد مثبت- بيش آزمون & \\
\hline.$/ 144$ &.$/ 191$ & $-\cdot / V \cdot S$ &.$/ .9 V$ & $1 / 9 \vee 1$ & $\Delta / r$ & 10 & كم اهميت شمارى - ييش آزمون & \\
\hline.$/ \cdots 1$ & $\cdot / r q 4$ & 1/Vm & $-\cdot / r s$. & l/AVr & 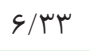 & 10 & فاجعه نمايى - بيش آزمون & \\
\hline$\cdot / \cdots \Delta$ & $\cdot /$ rş & $\cdot / 8 \mid 1$ & $\cdot / \Delta V G$ & $1 / 090$ & $\boldsymbol{f} / \boldsymbol{f}$ & 10 & سرزنش ديگران - يِيش آزمون & \\
\hline$\cdot / \cdot \Delta$ & $\cdot / r 19$ & $-1 /$ rᄉr & $\cdot /$ FVD & $r / \wedge \Delta$ & $r / \wedge V$ & 10 & سرزنش خود - پِ آزمون & \\
\hline$\cdot / \cdot \varphi \wedge$ & $\cdot / r r$ & $-\cdot / \vee 94$ & - / 1 Ars & r/Trs & $4 / 11$ & 10 & يذيرش - پِ آزمون & \\
\hline$\cdot / r$ &.$/ 181$ & $-1 / 4 \cdot \wedge$ & $\cdot / \cdot r F$ & $r / r 90$ & S/AV & 10 & تمركز بر فكر /نشخوارگرى- يس آزمون & \\
\hline$\cdot / \cdots 1$ & $\cdot /$ rqf & $\cdot, \mathcal{M Y}$ & $1 / 194$ & $r / r \Delta l$ & $r / V$ & 10 & تمر كز مجدد مثبت- يس آزمون & \\
\hline$\cdot / \cdot \Delta V$ & $\cdot / r \mid 9$ & $-1 / \mathbb{A} \wedge \varsigma$ & $\cdot 1011$ & $r / s \Delta \Lambda$ & $s / r V$ & 10 & تمركز مجدد بر برنامه ريزى- پس آزمون & \\
\hline$\cdot / r$ & $\cdot|| F \mid$ & $-1 / 1 \Delta \mu$ & $\cdot / \cdot \vee \wedge$ & $r / r G F$ & s/Dr & 10 & ارزيابى مجدد مثبت- يس آزمون & \\
\hline$\cdot / \cdot \Lambda$ & $\cdot / r \cdot \Lambda$ & $-\cdot 19 \cdot 4$ & $\cdot / 0 \cdots$ & $r / \mathcal{F V}$ & $\Delta / 4$ & 10 & كم اهميت شمارى- پِس آزمون & \\
\hline$\cdot / \cdot \mathrm{Vr}$ & $\cdot / 411$ & $-1 / r \wedge F$ & $-\cdot 1090$ & $1 / \wedge \wedge \Delta$ & $s / 1 \mu$ & 10 & فاجعه نمايى - يس آزمون & \\
\hline$\cdot / r$ & $\cdot / r \wedge F$ & $r / \mid F \Delta$ & $1 / 49 V$ & $r / \cdot \wedge \varphi$ & $r / r V$ & 10 & سرزنش ديگران- پِ آزمون & \\
\hline.$/ 119$ & $\cdot / 191$ & $-1 / 019$ & $\cdot /$ « ^ & $r / 9 \wedge V$ & $\Delta / r V$ & 10 & سرزنش خود - يِيش آزمون & \multirow{18}{*}{ كروه كنترل } \\
\hline$\cdot / r$ & $\cdot / 1 f$ & $-\cdot /$ VMr & $\cdot /$ Fro & $\Delta / \Delta r$ & $\Delta / \uparrow$ & 10 & يذيرش - بيش آزمون & \\
\hline$\cdot / \cdot r$ & $\cdot / r F$ & $-\cdot / \Delta \vee \Delta$ & $\cdot / 9 \Delta F$ & $\Delta / \mu / F$ & $\Delta / \mathrm{V}$ & 10 & تمر كز بر فكر /نشخوارگرى- يِش آزمون & \\
\hline$\cdot / 4$ & $\cdot / \mathrm{Vr}$ & $-\cdot / r \& \wedge$ & $\cdot$ /VYG & r/TFY & $r / \Lambda$. & 10 & تمركز مجدد مثبت - ييش آزمون & \\
\hline$\cdot / r$ & $\cdot / 101$ & $-1 / \cdot \Delta \mu$ & $-\cdot / \cdot \mathrm{k \mu}$ & $r / r \Delta s$ & $\Delta / \wedge \vee$ & 10 & تمر كز مجدد بر برنامه ريزى- بيش & \\
\hline$\cdot 1 \cdots 9$ & $\cdot / r \Delta V$ & $\cdot / \vee 91$ & $1 / .91$ & r/Trs & $r / \Delta r$ & 10 & ارزيابى مجدد مثبت- يِيش آزمون & \\
\hline$\cdot / \cdot \Delta F$ & $\cdot / r \mid \Lambda$ & $-\cdot / 9 V Y$ & . lsts & l/qFF & $p / 9 \mu$ & 10 & كم اهميت شمارى - يِ آزمون & \\
\hline . / rs & $\cdot / T r V$ & $-1 / \lambda \notin c$ & 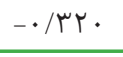 & $r / \boldsymbol{F} \wedge \mathrm{r}$ & s/OH & 10 & فاجعه نمايى - يِيش آزمون & \\
\hline$\cdot / r$ & $\cdot / \mathrm{VVV}$ & $-\cdot / 9 \cdot 0$ & $-\cdot / 1 \mu \cdot$ & $r / \Delta r$. & $0 / 9 \pi$ & 10 & سرزنش ديگران- يِيش آزمون & \\
\hline$\cdot / \cdots \Delta$ & $\cdot / r \& V$ & $-1 / V \hookrightarrow 4$ & $\cdot /$ rrs & $\mu / \cdot \wedge \varsigma$ & س & 10 & سرزنش خود - پس آزمون & \\
\hline$\cdot / \cdot \Delta r$ & $\cdot / r 19$ & $-\cdot /$ F VF & 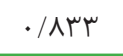 & r/rAF & $\Delta / r$ & 10 & يذيرش - يس آزمون & \\
\hline$\cdot / 4$ & $\cdot / 1 \mathrm{VV}$ & $-\cdot / 994$ & $\cdot / \mu \Delta \Lambda$ & $r / 919$ & $4 / \cdots$ & 10 & تمركز بر فكر /نشخوارگرى - يس آزمون & \\
\hline$\cdot / \cdot \mathrm{VI}^{\prime}$ & $\cdot / r 11$ &.$/ .9 V$ & $\cdot|\Lambda r|$ & I/VYV & $r / 1 \mu$ & 10 & تمر كز مجدد مثبت- يس آزمون & \\
\hline$\cdot / \cdot r V$ & $\cdot / r T V$ & $-\cdot / V \Psi V$ & $\cdot / \Delta \Delta \mu$ & r/s̆rV & س & 10 & تمر كز مجدد بر برنامه ريزى- يس آزمون & \\
\hline$\cdot / r$ & $\cdot / 1 \Delta r$ & $\cdot / 0 \mathrm{Vr}$ & $\cdot / F \Delta F$ & $1 / 090$ & $\boldsymbol{f} / \boldsymbol{q}$ & 10 & ارزيابى مجدد مثبت- پيس آزمون & \\
\hline.$/ \cdot 14$ & $\cdot / r \Delta 1$ & $-\cdot / 1 \wedge 9$ & $-\cdot / 49 \vee$ & $1 / \mathrm{V} \backslash 1$ & 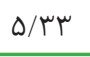 & 10 & كم اهميت شمارى- يس آزمون & \\
\hline$\cdot / 4$ & $\cdot / 1 \wedge$ & $-1 / \Delta F F$ & $-\cdot|\mathbb{F}| \cdot$ & r/rৎG & $G / S V$ & 10 & فاجعه نمايى - يس آزمون & \\
\hline$\cdot / 4$ & $\cdot / 1 s F$ & $-1 / \mu c V$ & $.1 \cdot 9 \mathrm{~V}$ & $r / F F$. & س & 10 & سرزنش ديگران- يس آزمون & \\
\hline
\end{tabular}


جدول س. آزمون تحليل كوواريانس مقايسه كَروهها در عزت نفس

\begin{tabular}{|c|c|c|c|c|c|c|}
\hline مجذور اتا & معنى دارى & $\mathbf{F}$ & ميانكين مجذورات & درجه آزادى & مجموع مجذورات & منبع تغييرات \\
\hline$\cdot / \Delta \cdot \mu$ & $\cdot / \cdot 1$ & r & $q \vee \backslash / r \mu q$ & 1 & $q \vee \backslash / r q 4$ & عزت نفس - يِيش آزمون \\
\hline \multirow[t]{3}{*}{.$/ 1 \mu}$. & $\cdot / \cdot \wedge r$ & r,צVq & $V I / \mu \cdot v$ & r & $|F r / s| F$ & كروه \\
\hline & & & $r S / S \mid 0$ & G & $9 \Delta \wedge / 1 Y q$ & خطا \\
\hline & & & & mq & $r \cdot G r / V V \Delta$ & كل \\
\hline
\end{tabular}

جدول عا. آزمون تحليل كوواريانس مقايسه گَروهها در تنظيم شناختى هيجان

\begin{tabular}{|c|c|c|c|c|c|c|c|}
\hline مجذور اتا ات & معنى دارى & $\mathbf{F}$ & مجذذورات & آزادى & مجذورات & 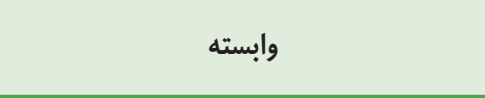 & تغييرات \\
\hline.$/ 1 r q$ &.$/ 145$ & $r / .94$ & N/৭99 & r & $1 V / 999$ & تمركز مجدد مثبت - بيش آزمون & \multirow{3}{*}{ كروه } \\
\hline$\cdot / \cdot r$. &.$/ 9 \Delta r$ & $\cdot / \mu_{\mu r}$ & $r / \wedge ९ \Delta$ & r & $\Delta / V \mu$ & تمركز مجدد بر برنامه ريزى- ييش آزمون & \\
\hline$\cdot / r 10$ &.$/ . \mu r$ & r/^rq & $19 / 9 r_{9}$ & r & $\mu r / \Lambda \Delta \Lambda$ & ارزيابى مجدد مثبت- ييش آزمون & \\
\hline.$/ \cdot \Delta$ & $\cdot / 4 \mathrm{Y} \wedge$ & $\cdot / V \Delta \Lambda$ & $r / 940$ & r & $\mathrm{V} / \wedge \wedge 9$ & سرزنش خود - ييش آزمون & \\
\hline$\cdot / \cdot V V$ & . Trd & $1 /|V|$ & r/QTF & r & $V / \cdot r \Lambda$ & يذيرش- بيش آزمون & \\
\hline$\cdot / \cdot r$ &.$/ 90 \wedge$ & $\cdot / \cdot \mu \mu$ &.$/ 194$ & r & $\cdot /$ r & تمركز بر فكر/نشخوارگرى - يِيش آزمون & \\
\hline.$/ \cdot 14$ & ./Arr &.$/ 199$ & $\cdot / \Lambda \cdot r$ & r & $1 / 9 \cdot 9$ & كم اهميت شمارى- يِيش آزمون & \\
\hline$\cdot / \cdot \wedge 1$ & $\cdot / \mu \cdot \Delta$ & $1 / r \mu q$ & $\Delta / 9 r$. & r & $11 / r F$. & فاجعه نمايى- يِيش آزمون & \\
\hline \multirow[t]{19}{*}{.$/ .1 \mathrm{~V}$} & . JAr & $\cdot / r F q$ & $1 / 4 \wedge F$ & r & $r / 94 \Lambda$ & سرزنش ديگران- بيش آزمون & \\
\hline & & & $r / \mu \Delta s$ & rA & $|r| / 9 V r$ & تمر كز مجدد مثبت - ييش آزمون & \multirow{9}{*}{ 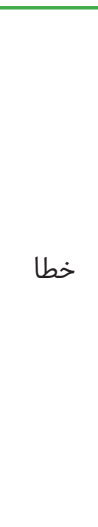 } \\
\hline & & & $9 / 099$ & rᄉ & IAF/VG. & تمركز مجدد بر برنامه ريزى- ييش آزمون & \\
\hline & & & $p / q \cdot q$ & rᄉ & $\mid r r / 4 G$. & ارزيابى مجدد مثبت - ييش آزمون & \\
\hline & & & $\Delta / r \cdot 1$ & rᄉ & IFD/GTS & سرزنش خود - بيش آزمون & \\
\hline & & & $r / \cdots \wedge$ & rA & $\Lambda F / r Y \Lambda$ & بذيرش- بيش آزمون & \\
\hline & & & $\mathcal{F} / \mathcal{F} \wedge \vee$ & rی & IrD/GrT & تمركز بر فكر /نشخوارگرى - ييش آزمون & \\
\hline & & & $r / 1.9$ & ru & $11 f / 9 v$ & كم اهميت شمارى- يِيش آزمون & \\
\hline & & & r/oro & ru & $1 \% 8 / 99$. & فاجعه نمايى - يِش آزمون & \\
\hline & & & $\Delta / q \vee$. & rᄉ & $19 V / 1 \Delta 0$ & سرزنش ديگران- بيش آزمون & \\
\hline & & & & rq & IAY/VVD & تمركز مجدد مثبت - ييش آزمون & \multirow{9}{*}{ كل } \\
\hline & & & & rq & $r \in \Gamma / \Delta \ldots$ & تمر كز مجدد بر برنامه ريزى- ييش آزمون & \\
\hline & & & & rq & $r r s / 4 .$. & ارزيابى مجدد مثبت - ييش آزمون & \\
\hline & & & & rq & rq1/VVD & سرزنش خود - بيش آزمون & \\
\hline & & & & rq & rMT/VVD & يذيرش - بيش آزمون & \\
\hline & & & & rq & rmו/s.. & تمركز بر فكر/نشخوارگرى- ييش آزمون & \\
\hline & & & & rq & $199 / 0 \ldots$ & كم اهميت شمارى- يِش آزمون & \\
\hline & & & & rq & $r \wedge 1 / \Delta \ldots$ & فاجعه نمايى- يِيش آزمون & \\
\hline & & & & rq & $r \Delta 1 / 9 .$. & سرزنش ديگران- يِيش آزمون & \\
\hline
\end{tabular}


جدول ه. آزمون تحليل كوواريانس مقايسه گَروهها در رفتار خود جرحى

\begin{tabular}{|c|c|c|c|c|c|c|}
\hline مجذور اتا & معنى دارى & $\mathbf{F}$ & ميانگين مجذورات & درجه آزادى & مجموع مجذورات & منبع تغييرات \\
\hline$\cdot / F \vee I$ & $\cdot / \cdots 1$ & $r r / \cdot r \Delta$ & $90 / 191$ & 1 & $90 / 191$ & رفتار خود جرحى - يِش آزمون \\
\hline \multirow[t]{3}{*}{ 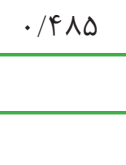 } & $\cdot / \cdot 1$ & $19 / 9 \vee 0$ & $\Delta \cdot / \mathbb{F} \Delta V$ & r & $1 \cdots / 910$ & 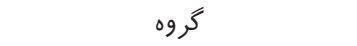 \\
\hline & & & $r / 9 \vee r$ & rs & $1 \cdot V / \cdots 4$ & 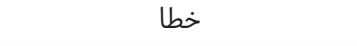 \\
\hline & & & & rq & $r F 1 / G \ldots$ & كل \\
\hline
\end{tabular}

بحث و نتيجها كيرى

است، به طور ميانكين، عزت نفس در دوران كودكى نسبتأ بالاست يا زياد است. در دوران نوجوانى دجار افت مىشود (مخصوصا در درد

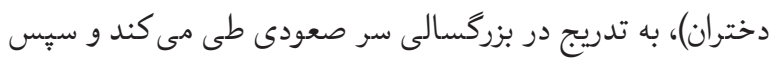
با شيب تندى در كهنسالى يا سالمندى افت مى كند (Tسا). بر همين اساس با توجه به اينكه در دوران نوجوانى عزت نفس سير نزولى دارد

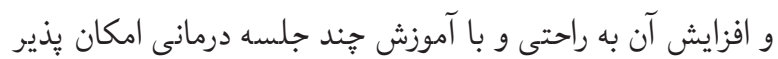

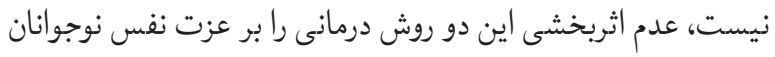

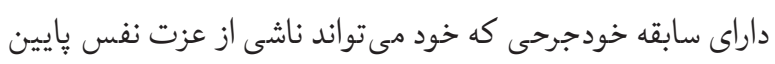

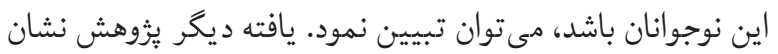

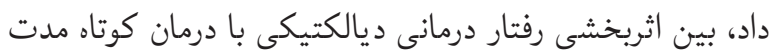

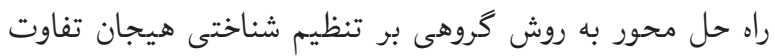
معنى دارى وجود دارد. مقايسه هاى بونغورنى در خرده مقياسهاى

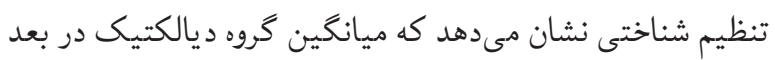
ارزيابى مجدد مثبت به طور معنى دارى بالاتر از ميانكين كروه كنترل است. بين ميانكين گروه ديالكتيك با گروه راه حل محور و گروه راه حل محور با گروه كنترل تفاوت معنى دارى وجود ندارد. فرضيه سوم بروهش با اين يافته تاييد مىشود. به عبارت ديكر،

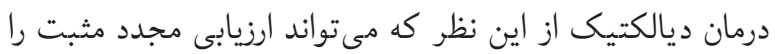

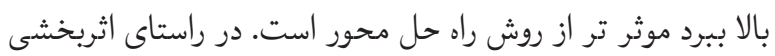

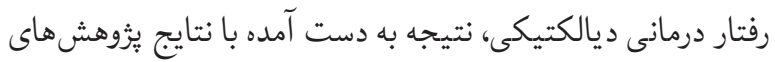
Babaei

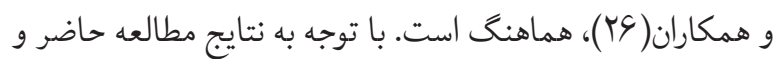
از سوى ديكر با نكاهى به ئوهش هاى بيشين و تاثير روش هاى

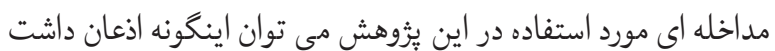

رفتار خودجرحى غيرخودكشى مسئلهاى جدى است كه تأثير نامطلوبى

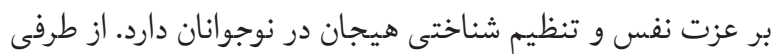

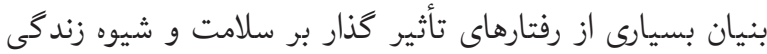

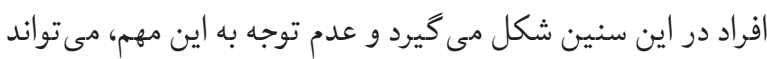

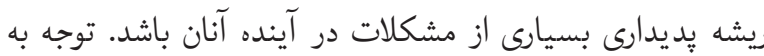

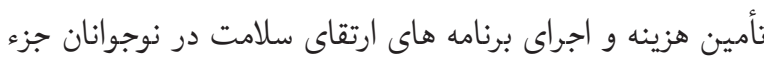
مهمترين بخش برنامه هاى سلامت نسل حاضر مى باشد؛ لذا انجام

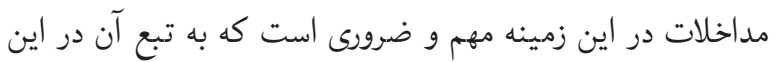
يُوهش مقايسه اثربخشى رفتار درمانى ديالكتيكى با درمان كوتاه

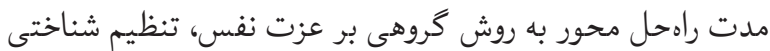
هيجان و رفتار خودجرحى غير خودكشى، در بين دانش آموزان دختر مقطع متوسطه اول شهر برديس انجام شد. يافتهها نشان داد كه بين اثربخشى رفتار درمانى ديالكتيكى با درمان كوتاه مدت رداه

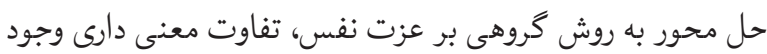

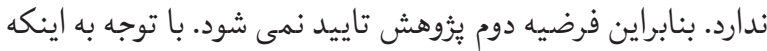

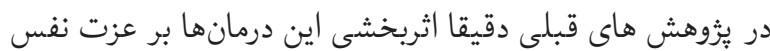
دختران داراى سابقه خودجرحى مورد بررسى قرار نكرفته است امكان

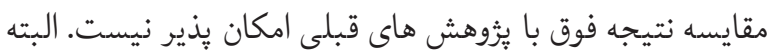

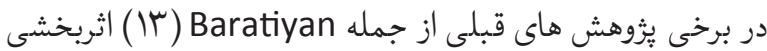
اين درمان بر عزت نفس مورد تاييد قرار گرفته است اما روى نمونه ترونه داراى سابقه خودجرحى كار نشده است. در تبيين احتمالى عدم تاييد

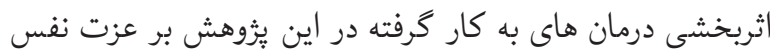

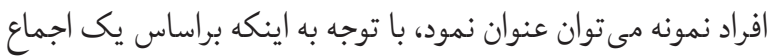
نظرى كه در مورد سير تحول عزت نفس در طول زندگى بدست آمده 
كه در مورد اثربخشى مناسب درمان ديالكتيك بر كاهش رفتارهاى خود جرحى، وجود پاره ایى از ويز كى هاى متمايز كننده اين درمان

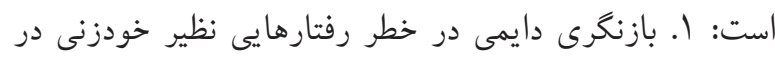

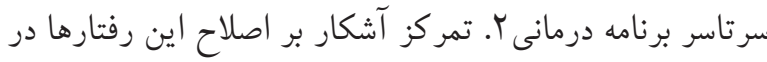

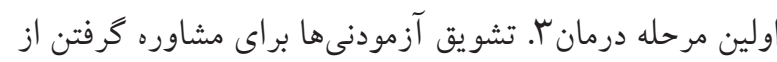

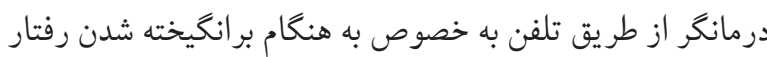

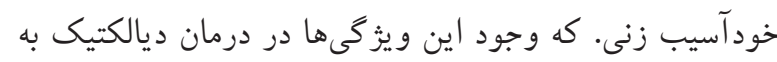

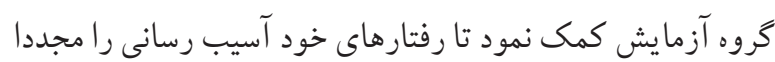

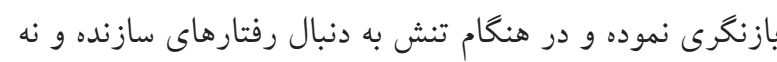
مخرب براى كاهش اين تنشها باشند.

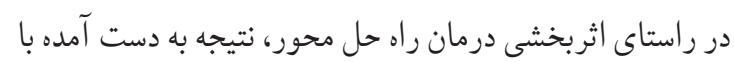

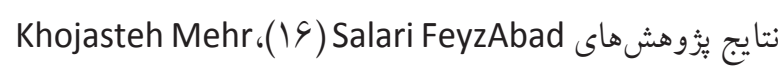

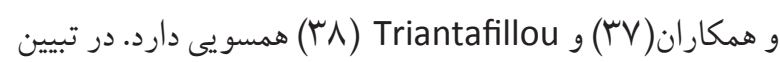
علت اثربخشى درمان راه حل محور مى توان گفت كه مشاوره راه حل

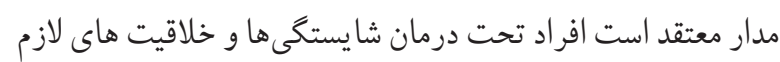

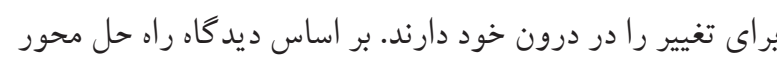
تغيير و دكر گونى، امرى اجتناب نايذير بوده و مخصوصاً تغييرات

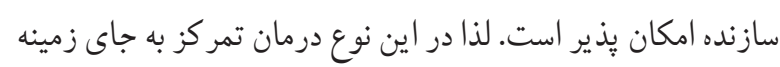
هاى سخت و غيرقابل تغيير بر روى مسايلى است كه احتمال تغيير

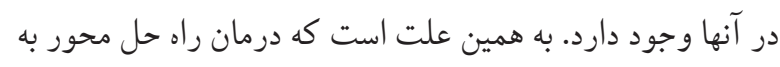

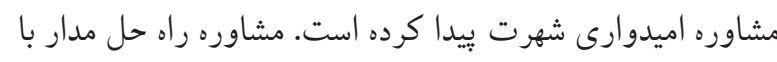

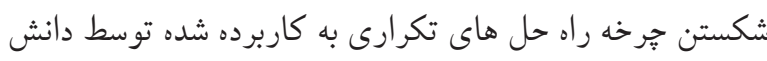

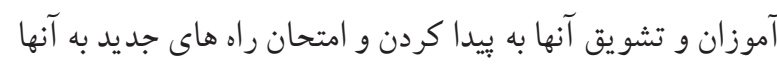

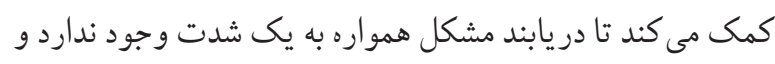

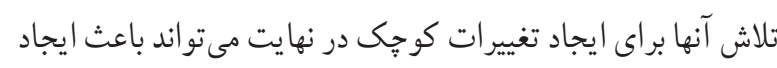

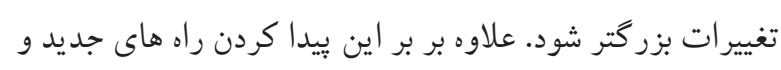

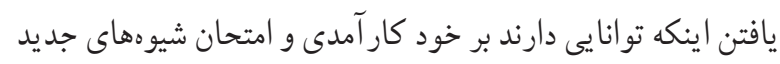

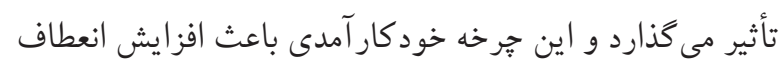

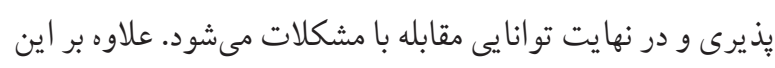

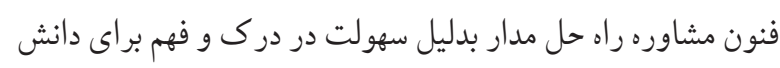

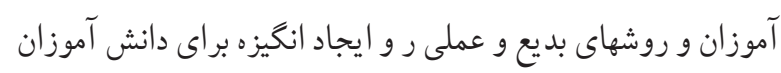

كه روش رفتار درمانى ديالكتيك با برونريزى هيجانهاى محصور شده و آموزش تعديل هيجانى كه منجر به تنظيم هيجانها دئ دونى شود.

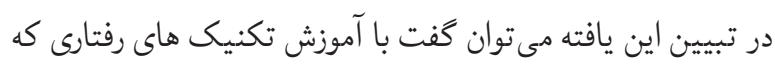

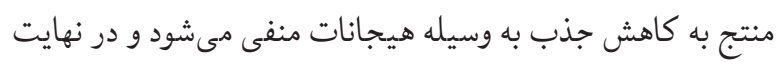

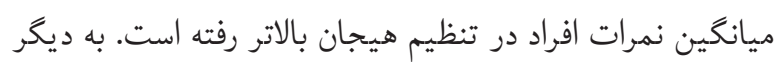

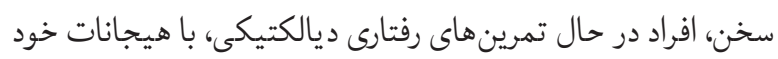

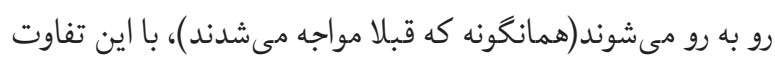
كه بعد از آموزشهاى ديالكتيكى، ابزار لازم براى رويارويى را دارند.

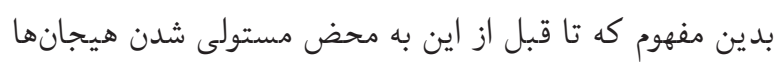

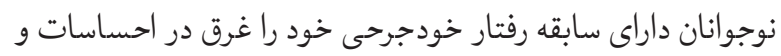

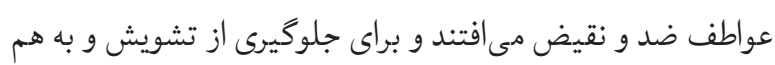

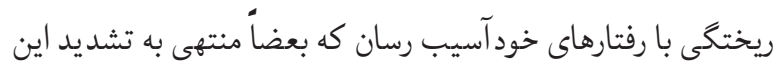

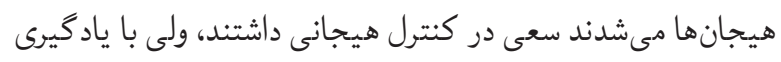

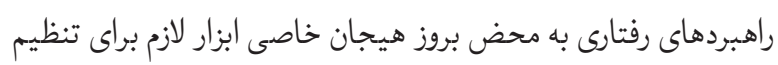

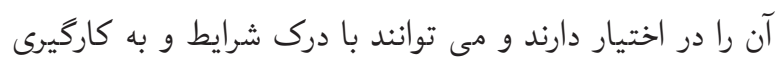

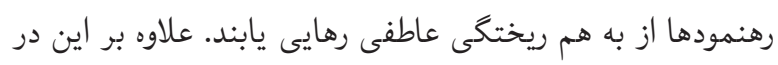

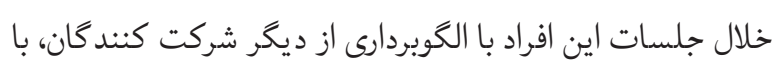
هيجانات خود بيشتر آشنا مىشوند كه داشتن اين آكاهى مى تواند در تنظيم هيجانات آنان بسيار مفيد واقع گردد. (YV).

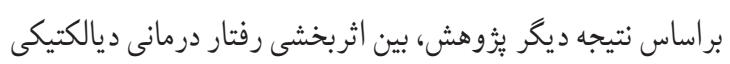

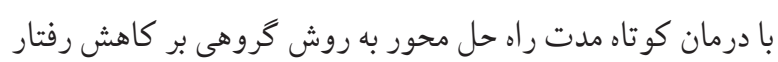
خود جرحى، تفاوت معنى دارى مشاهده شد. ميانكين نمر ات رفتار

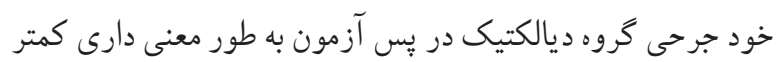

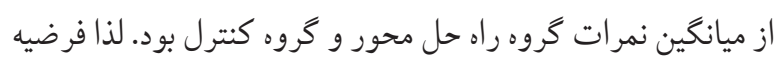

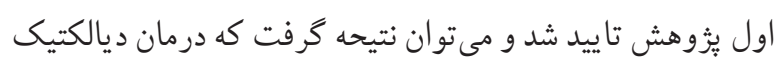
موثرتر از درمان راه حل محور و هر دو درمان بهتر از عدم درمان است.

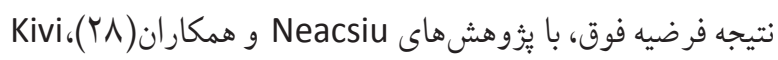
Ghomri

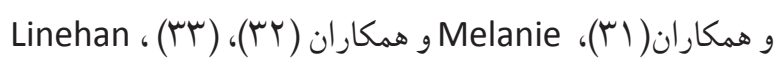
Fleischhaker و هafari 
مى تواند اثربخش باشد. همجنين مسئولان و دست اندر كاران

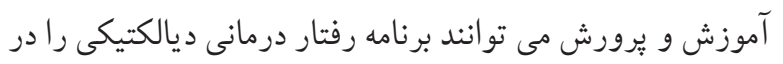

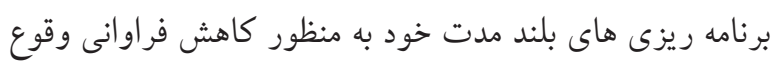

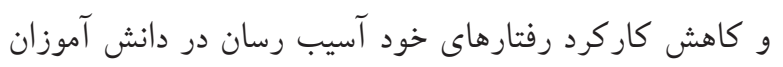

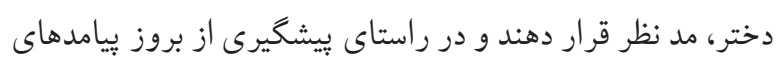

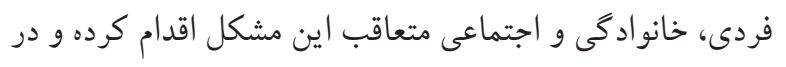
بسيارى از هز ينه هاى انسانى و مادى تحميل شده به مراجع و نهاد هاى ذينفع صرفه جويى كنند؛ جرا كه اين دانش آموزان، والدين

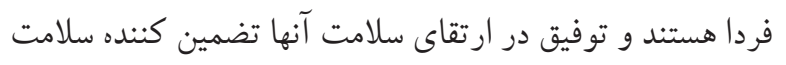

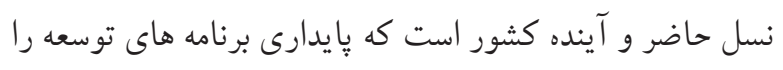
به دنبال دارد. بنابراين لازم است جهت تحقق اين اهداف به تمام

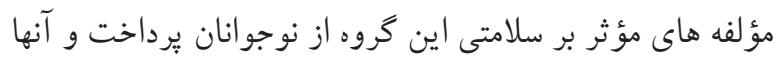

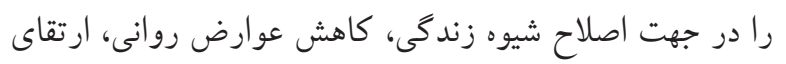

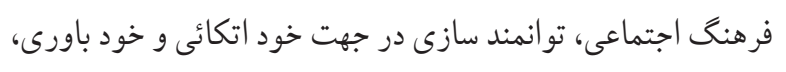
افزايش عزت نفس، خو يشتن دارى و سازش يذيرى تجهيز نمود.

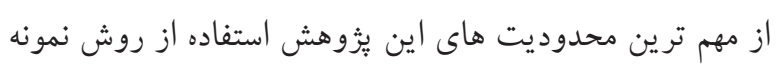
كيرى در دسترس بود و نبود مرحله بيخيرى براى اطمينان از نتايج بلندمدت تأثير و مقايسه رفتار درمانى ديالكتيكى با درمان كوتاه

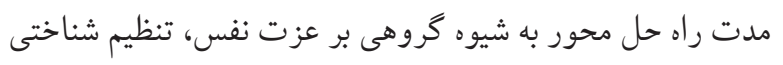

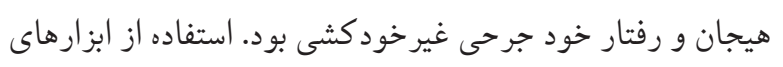

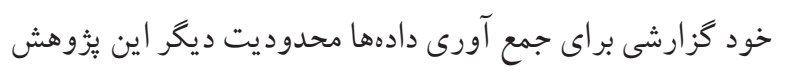

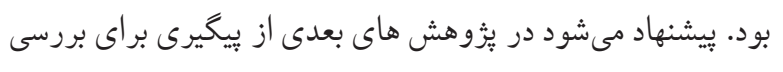

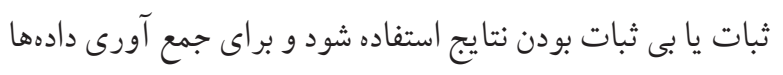
از مصاحبه هاى ساختار يافته يا نيمه ساختار يافته استفاده شود.

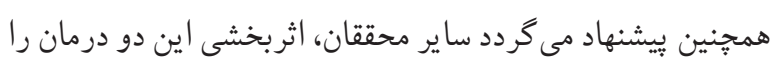

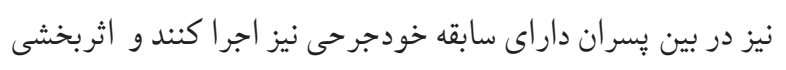

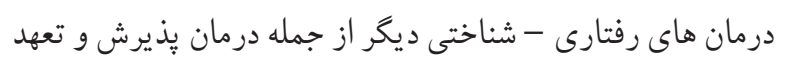
را بر كاهش رفتارهاى خود آسيب رسانى مورد مطالعه قرار دهند.

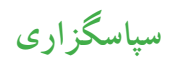
مقاله حاضر مستخرج از يايان نامه كارشناسى ارشد رشته روان

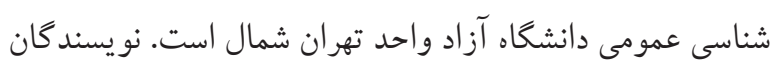

در ابعاد مختلف مى كوشد تا تغيير را امكان بذير سازد. علاوه بر اين ايجاد رابطه حسنه در طول مداخله، تشويق به كَتكو و بيان خواسته ها، وجود جوى مناسب، و تشويق آنها به ساخت راه حلهايى بجز

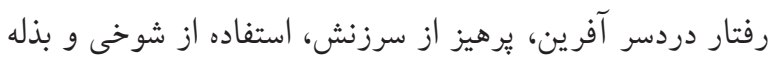

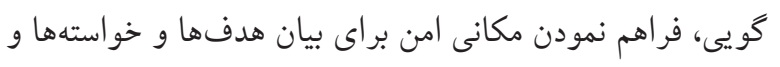

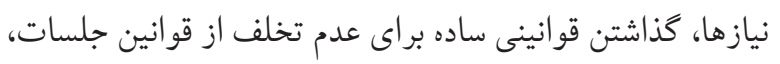
خود باعث ايجاد فضايى دوستانه و همدلانه شد كه مى توانند در تبيين اثربخشى مثبت اين درمان مؤثر باشد. تحقيقات بر ديدكاه

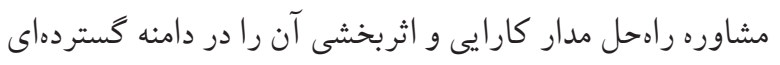

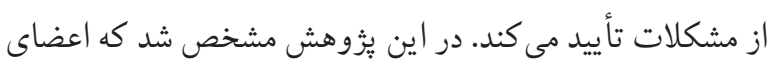

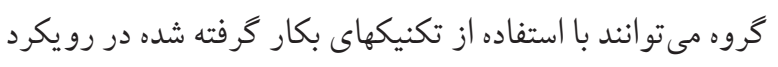

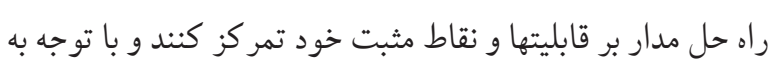

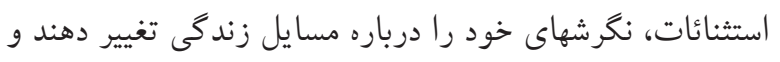
به نتايج مثبتى دست يابند. در واقع كمك به افر اد براى يافتن آن

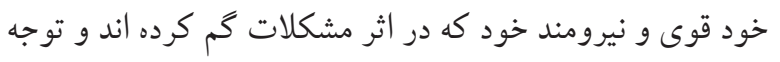

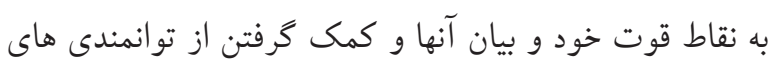
خود به جاى تكيه بر منابع بيرونى و يافتن جواب سؤ الات در درون

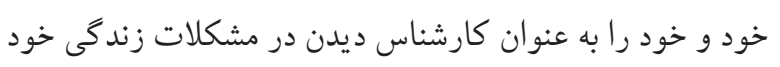
و اظهارنظر در اين مورد مىتواند تبيين كر نتايج باشد. نتيجاه كيرى يافتهها نشان داد، رفتار درمانى ديالكتيكى و آموزش كوتاه

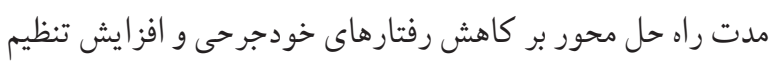
شناختى هيجان دانش آموزان دختر داراى سابقه خودجرحى، تاثير داني

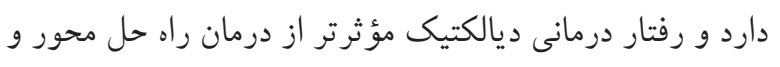

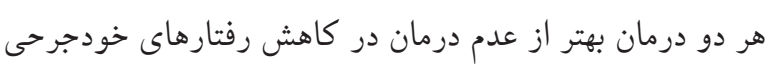

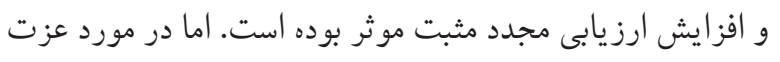
نفس، تفاوت معنى دارى بين رفتار درمانى ديالكتيكى و آموزش كو تاه مده راه حل محور مشاهده نشد. در نتيجه طر احى و تدو دورين

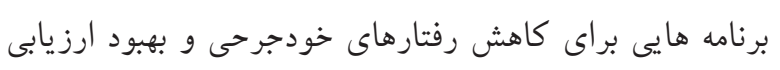

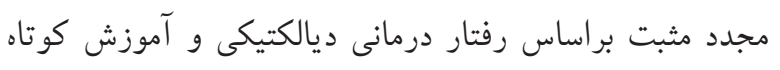

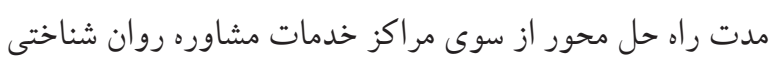




$$
\text { تضاد منافع سهم تمامى نويسند كان در اين مطالعه يكسان است و هيج كونه }
$$

\section{References}

1- Dalaki F. Psychology of child and adolescent development. Tehran: khorosh; 2010.

2- Favazza AR. The coming of age of self-mutilation. Journal of nervous and mental disease. 1998; 186,259-278. https://doi.org/10.1097/00005053-199805000-00001 PMid:9612442

3-KlonskyED. The functions of deliberate self-injury: A review of theevidence. Clinical psychology Review. 2007;27,226-239. https://doi.org/10.1016/j.cpr.2006.08.002 PMid:17014942

4- Amirzadegan M. "Effectiveness of dialectical behavioral therapy on self-esteem and self-efficacy of obese women". Master's thesis, Islamic Azad University of Roudehen; 2013.

5- Gross JJ. The emerging field of emotion regulation: An integrative review. Review of general psychology. 1998 Sep;2(3):271-99. https://doi.org/10.1037/1089-2680.2.3.271

6- Thompson RA. Emotion regulation: A theme in search of definition. Monographs of the society for research in child development. 1994 Feb;59(2-3):25-52. https://doi.org/10.1111/j.1540-5834.1994.tb01276.x PMid:7984164

7- Cicchetti D, Ackerman BP, Izard CE. Emotions and emotion regulation in developmental psychopathology. Development and psychopathology. 1995;7(1):1-10. https://doi.org/10.1017/S0954579400006301 https://doi.org/10.1017/\$0954579400006933

8. Narimani M. Abbasi M. Comparison of the Effectiveness of Acceptance and Commitment Training with Exercise Therapy Training on Psychological Well-being, Adaptability and Risky Behaviors of Students with Mental Disorders. Learning Disabilities, 2011; 2 (4), 154- 176

9- Dimeff LA, Koerner K. Dialectical Behavior Therapy in Clinical Practice: Applications across Disorders and Settings, Guilford Press, New York City; 2007.

10- Linehan MM. Skills training manual for treating borderline personality disorder New York: Guilford.

11- Becvar DS, Becvar R. Family therapy: A systemic integration (5th ed). Needham Heights, MA: Allyn \& Bacon; 2003.

12- Salari FeyzAbad $H$. The effect of counseling on problemcentered counseling on psychological decline and its syndrome among high school students in Andisheh city in the academic year of 85-86. Shahid Beheshti University,

$$
\begin{aligned}
& \text { مقاله از مسئولين مدارس دخترانه دوره متوسطه اول شهرستان يرديس } \\
& \text { و همه كسانى كه جهت اجراى اين يزوهش همكارى صميمانه اى } \\
& \text { را با يُزوهشخران داشتند، تشكر و قدردانى مى كنند. }
\end{aligned}
$$

Faculty of Psychology and Educational Science; 2007.

13- Baratiyan A, Salimi A, Moghim F, Shakrami M, Davarniya R. Effect of short-term solution-based treatment on increasing self-esteem of female students. Journal of Nursing Research. $2015 ; 11$ (4) 64-57. https://doi.org/10.21859/ijnr-110407

14- World Health Organization. Mental Health Atlas.Geneva, World Health Organization; 2005.

15- Nock, M. K. Actions speak louder than words: An elaborated theoretical model of the social functions of self-injury and other harmful behaviors. Applied and Preventive Psychology, 2008; 27(2): 215-240.

16- Ross, Sh \& Heath, N. A Study of the Frequency of SelfMutilation in a Community Sample of Adolescents. Journal of Youth and Adolescence, 2002; 31(1): 67-77. https://doi.org/10.1023/A:1014089117419

17- Paivastegar, $M$. The rate of deliberate self- harming in girls' students and relationship with loneliness \& Attachment styles. Journal of Psychological Studies, 2013; 9(3): 29-52.

18- Biybangard E. The Relationship Between Self-esteem, Extension Motivation and Academic Achievement in ThirdYear Students of High Schools in Tehran. Psychological Studies, Scientific-Research, 2005;4(5):131-144.

19- Hormozi Nezhad M. Simple and multiple relationship between self-esteem, social anxiety and perfectionism with self-expression in students of Ahwaz Shahid Chamran University. Master's thesis, Educational Psychology, Faculty of Educational Sciences and Psychology, Shahid Chamran University of Ahvaz; 2000.

20- Garnefski N, Kraaij V. Cognitive emotion regulation questionnaire-development of a short 18item version (CERQ-short). Personality and individual differences. 2006;41(6),1045-1053. https://doi.org/10.1016/j.paid.2006.04.010

21- Beshtarat MR, Bazaziyan S. Psychometric Properties of the Think Tunnel Questionnaire in a Sample of Iranian Society. Journal of Nursing and Midwifery Faculty, 2013;24(84), 61-70.

22-KlonskyED, OlinoTM. dentifying clinically distinct subgroups of self-injurers among young adults: a latent class analysis. Journal ofconsulting and clinical psychology, 2008;76(1), 22. https://doi.org/10.1037/0022-006X.76.1.22 PMid:18229979

23-TrzesniewskiKH, RobinsRW.Acohort-sequentialstudyofself- 
esteem from age 25 to 96 . Poster presented at the Society for Personality and Social Psychology. Austin, Texas; 2004. https://doi.org/10.1037/e633912013-233 PMid:26804578

24. Babaei L, Fakhri MK, Jadidi M, Salehi Omran MT. Effectiveness of dialectical behavioral therapy on emotional regulation and perceived social support in coronary artery bypass grafters. Journal of Babol University of Medical Sciences,2013;17(11):27-21.

25- Schnell K, Herpertz SC. Effects of dialectical behavior therapy on the neural correlates of affective hyperarousal in borderline personality disorder. Journal of psychiatric research. 2006; 41(10): 837-847. https://doi.org/10.1016/j.jpsychires.2006.08.011 PMid:17064731

26. Nadimi M. The effectiveness of group dialectical behavioral therapy in increasing the tolerance of distress and improving the emotional regulation of substance abuse. Etiadpajohi,2016; 9(36), 141-160.

27- Linehan MM, Dimeff LA, Reynolds SK, Comois KA, Welch SS, Heagerty $P$, et al. Dialectical behavior therapy versus comprehensive validation therapy plus 12-step for the treatment of opioid dependent women meeting criteria for borderline personality disorder. Drug Alchohol Depend, 2008; 67(5): 13-29. https://doi.org/10.1016/S0376-8716(02)00011-X

28- Neacsiu AD, Rizvi SL, Linehan MM. Dialectical behavior therapy skills use as a mediator and outcome of treatment for borderline personality disorder. Behavior Research and Therapy. 2010; 48(9): 832-9. https://doi.org/10.1016/j.brat.2010.05.017 PMid:20579633 PMCid:PMC2914145

29- Ghomri Kivi H, Senobar L, Ahadi S. The Effectiveness of Dialectical Behavioral Therapy on Self-Corruption and Swinging the Creation of Borderline Personality Disorder. Personality Quarterly and Individual Differences, 2013; 3(6), 93-111.

30- Bohus M, Haaf B, Simms T, Limberger MF, Schmahl C, Unckel C. Effectiveness of inpatient dialectical behavioural therapy for borderline ponality disorder: A controlled trial. Journal of Behaviour Research \& Therapy. 2004;42(5), 487-499. https://doi.org/10.1016/S0005-7967(03)00174-8

31- Clarkin JF, Leavy KN, Kernberg OF, Lenzenwerger MF. Evaluating three treatments for borderline personality disorder. Am Journal of Psychiatry, 2007; 164, 922-928. https://doi.org/10.1176/ajp.2007.164.6.922 PMid:17541052

32- Melanie S., Harned E, Korslund EB, Foa M, Linehan M. Treating PTSD in suicidal and self-injuring women with borderline personality disorder: Development and preliminary evaluation of a Dialectical Behavior Therapy Prolonged Exposure Protocol. journal of Behaviour Research and Therapy, 2012; (50), 381-386. https://doi.org/10.1016/j.brat.2012.02.011 PMid:22503959 PMCid:PMC3348973

33- Linehan MM, Bohus M, Lynch T. Dialectical behavior therapy for pervasive emotion dysregulation: Theoretical and practical underpinnings. In, Gross, James J. (ed.) Handbook of Emotion Regulation. New York, US. Guilford Press 2007, 581-605.

34- Fleischhaker $\mathrm{CH}$, Bohme $\mathrm{R}$, Sixt $\mathrm{B}$, Bruck $\mathrm{CH}$, Schneider C) Schulz E. Dialectical Behavioral Therapy for adolescents (DBT-A): a clinical Trial for Patients with suicidal and self-injurious Behavior and Borderline Symptoms with a one-year Follow-up. Child and Adolescent Psychiatry and Mental Health, 2011; 5:3. https://doi .org/10.1186/1753-2000-5-3 PMid:21276211 PMCid:PMC3037874

35- Mazaheri MA, Bardjali A, Ahadi H and Golshani F. Effectiveness of dialectical treatment behavior in the treatment of borderline personality disorder. Psychological research. 2010; (2), 25-1

36- Safari Nia M, Nikoghftar M, Damavandian A. The Effectiveness of Dialectical Behavioral Therapy on Reducing Self-Damaging Behaviors in Juvenile Offenders in Tehran's Rehabilitation Center. Clinical Psychology Studies. 2013; 15 (4), 158-141

37- Khojasteh Mehr R, Abbaspour Z, Rajabi Gh, Alipour S, Attari Y, Rahmani AH. Effectiveness of family-centered cognitive-behavioral therapies and decision-centered on suicidal thoughts, depressive symptoms, family affiliation and suicidal attempts Suicidal attempts. Quarterly Journal of Family Counseling and Psychotherapy, 2013; 4(2):185226.

38- Triantafillou N. A solution-focused approach to mental health supervision. Journal of Systemic Therapies 1997; 16(4): 305-328. https://doi.org/10.1521/jsyt.1997.16.4.305 